OPEN ACCESS

Edited by:

Pinyi Lu,

Frederick National Laboratory for Cancer Research (NIH),

United States

Reviewed by:

Alberto Valdés,

Consejo Superior de Investigaciones Cientificas (CSIC), Spain

Likui Feng,

The Rockefeller University,

United States

*Correspondence:

Kai Wang

kaiwang628@gmail.com

Liming Wu

apiswu@126.com

Specialty section: This article was submitted to Nutritional Immunology, a section of the journal Frontiers in Immunology

Received: 23 February 2021 Accepted: 07 June 2021

Published: 02 July 2021

Citation:

Zhang W, Qi S, Xue X, Al Naggar Y, Wu $L$ and Wang $K$ (2021)

Understanding the Gastrointestinal

Protective Effects of Polyphenols using

Foodomics-Based Approaches.

Front. Immunol. 12:671150.

doi: 10.3389/fimmu.2021.671150

\section{Understanding the Gastrointestinal Protective Effects of Polyphenols using Foodomics-Based Approaches}

\author{
Wenwen Zhang ${ }^{1}$, Suzhen $Q i^{1}$, Xiaofeng Xue ${ }^{1}$, Yahya Al Naggar ${ }^{2,3}$, Liming $W^{1 *}$ \\ and Kai Wang ${ }^{1 *}$ \\ ${ }^{1}$ Institute of Apicultural Research, Chinese Academy of Agricultural Sciences, Beijing, China, ${ }^{2}$ Zoology Department, Faculty \\ of Science, Tanta University, Tanta, Egypt, ${ }^{3}$ General Zoology, Institute for Biology, Martin Luther University Halle-Wittenberg, \\ Halle (Saale), Germany
}

Plant polyphenols are rich sources of natural anti-oxidants and prebiotics. After ingestion, most polyphenols are absorbed in the intestine and interact with the gut microbiota and modulated metabolites produced by bacterial fermentation, such as short-chain fatty acids (SCFAs). Dietary polyphenols immunomodulatory role by regulating intestinal microorganisms, inhibiting the etiology and pathogenesis of various diseases including colon cancer, colorectal cancer, inflammatory bowel disease (IBD) and colitis. Foodomics is a novel high-throughput analysis approach widely applied in food and nutrition studies, incorporating genomics, transcriptomics, proteomics, metabolomics, and integrating multi-omics technologies. In this review, we present an overview of foodomics technologies for identifying active polyphenol components from natural foods, as well as a summary of the gastrointestinal protective effects of polyphenols based on foodomics approaches. Furthermore, we critically assess the limitations in applying foodomics technologies to investigate the protective effect of polyphenols on the gastrointestinal (Gl) system. Finally, we outline future directions of foodomics techniques to investigate Gl protective effects of polyphenols. Foodomics based on the combination of several analytical platforms and data processing for genomics, transcriptomics, proteomics and metabolomics studies, provides abundant data and a more comprehensive understanding of the interactions between polyphenols and the Gl tract at the molecular level. This contribution provides a basis for further exploring the protective mechanisms of polyphenols on the Gl system.

Keywords: plant polyphenols, foodomics, polyphenols, gastrointestinal system, gut microbiota

\section{INTRODUCTION}

Polyphenols are a subclass of phytochemicals, abundantly found in natural products. They are plantbased secondary metabolites that normally contain at least one or more hydroxyl group-linked benzene rings. The chemical structure of polyphenols varies from simple molecules to highly polymerized compounds, including flavonoids, phenolic acids, proanthocyanidins and resveratrol (1). Polyphenols have multiple health benefits owing to their anti-inflammatory (2), anti-oxidant (3), 
anti-cancer (4), anti-bacterial (5), and anti-diabetic properties (6), inhibition of obesity, and prevention of cardiovascular (7) and cerebrovascular diseases (8). Thus, current scientific research on polyphenols has aroused great interest and significantly attracted the attention of researchers.

The beneficial effects of dietary polyphenols on health depend on their absorption and bioavailability in the body (9). The gastrointestinal (GI) tract is an indispensable digestive organ whose function is crucial to the host's health, as it regulates the absorption and utilization of nutrients by the body (10). Maintaining good health requires a fully functioning digestive system. A damaged GI system, obstructs GI function, which affects the absorption and utilization of nutrients and thereby threatens host health (11). Gut microbiota are a microbial community inhabiting the GI tract, constituting multiple species that are densely distributed, at approximately $10^{14}$ microbial cells (12). Gut microbiota are critical to gut health and fulfill multiple tasks in the host (13). They are affected by various internal and external factors, including diet, genetics, and external environmental factors (14).

Most polyphenols found in the natural food matrix are mostly bound and unbound, with the majority of them in the form of bound polyphenols (15), and these polyphenol compounds are considered xenobiotics because of their complex chemical structure, making them difficult to absorb after ingestion (16, 17). Consequently, portions of polyphenols are stored in the large intestine, where they are fermented by the gut microbiota, raising the concentration of short-chain fatty acids (SCFAs) to selectively modulate gut microbiota that can be used by the host (18). Metabolites produced by the catabolism of polyphenols in the intestine may be more bioavailable to gut microbiota and hosts (19). Numerous studies demonstrated that polyphenols maintain gut health by interacting with the gut microbiota (20).

Polyphenols and gut microbiota have interactive effects (21). On the one hand, polyphenols retained in the colon are absorbed and metabolized by gut microbiota and biotransformed into their metabolites, significantly improving bioavailability (22). On the other hand, polyphenols act as a metabolic prebiotics (23), and studies indicate that dietary polyphenols may affect gut microbiota through dual positive effects to benefit GI health, namely, the inhibition of pathogenic microbiota and enrichment of beneficial microbiota (17). When the number of beneficial microbiota in the gut is greater than the number of harmful microbiota, the GI tract's role and health can be preserved. Therefore, polyphenols ingested at specific concentrations may help maintain GI health by modulating the gut microbiota composition (24). Numerous studies showed that plant polyphenols can alleviate inflammatory bowel disease (IBD) and achieve anti-inflammatory effects by interacting with gut microbiota (19). However, our understanding of the mechanisms by which dietary polyphenols modulate gut microbiota composition and the beneficial effects of polyphenols on the GI tract is severely limited.

The comprehensive discipline of foodomics was first defined in 2009 by Cifuentes (25) as the study and analysis of the fields of food and nutrition using advanced omics technologies (such as genomics, proteomics, metabolomics, and transcriptomics), to promote consumer trust and health. Integrating these techniques enable researchers to establish links between diet and health. Recent decades have witnessed rapid growth of various applications of foodomics technologies for investigating the beneficial activities of polyphenols on gut health (26). The aim of this review is to further elucidate the growing number of contributions that use the foodomics approach to assess relevant aspects related to the protective effects of polyphenols on GI health, such as: 1) identifying polyphenols and their metabolites after ingestion using GC-MS-and LC-MS/MS-based metabolomics approaches; 2) using genomic/transcriptomic approaches to determine gene expression/transcription and the interactions between genes and polyphenols; 3) exploring protein expression patterns in response to polyphenols in the GI; 4) combining several omics approaches to determine network changes that exist at the cell, tissue, or whole organism level. An overview of integrated foodomics approaches for better understanding the interactions between polyphenols, gut microbiota, and host health is presented in Figure 1.

\section{POLYPHENOLS IN THE DIET ARE BENEFICIAL TO GI HEALTH}

Dietary polyphenols have been linked to a number of health benefits in the GI tract. Upon reaching the GI tract, part of the dietary polyphenols is absorbed by the intestinal barrier and extensively metabolized in tissues, however, the non-absorbed polyphenols from the small intestine are retained in the colon (27). Most dietary polyphenols are retained in the GI tract as xenobiotics and interact with the microbial community in the intestine during digestion. The variations in polyphenol intake available for absorption and metabolism in the GI tract are dependent on their structures. Polyphenols retained in the GI tract are usually catabolized by gut microbiota (28), and the composition of gut microbiota may also result in differences in the metabolism and bioavailability of polyphenols and their metabolites (29). Polyphenols are metabolized via glucosidase, esterase, dehydroxylation, decarboxylation and demethylation activities by gut microbiota to various derivatives (21), all of which further improve the bioavailability of polyphenols and enhance the benefits to GI health.

Polyphenols play an immunomodulatory role by regulating intestinal microorganisms. The gastrointestinal tract contains a large number of macrophages and neutrophils, which play an immunomodulatory role in the immune system through recognition, uptake, and destruction of intestinal microorganisms (30). The immune system interacts with intestinal microorganisms to maintain the health of the gastrointestinal tract, and polyphenols improve the cellular immune response by regulating these intestinal microorganisms and immune factors, which together maintain a healthy balance in the gastrointestinal tract (31). Indeed, multiple studies have addressed the protective effects of polyphenols on the GI tract (17), dietary polyphenols play a prominent role in altering the gut microbiota, improving barrier function, and inhibiting the etiology and pathogenesis of various diseases, including colon cancer, colorectal cancer (32), IBD, and colitis (33). Polyphenols 


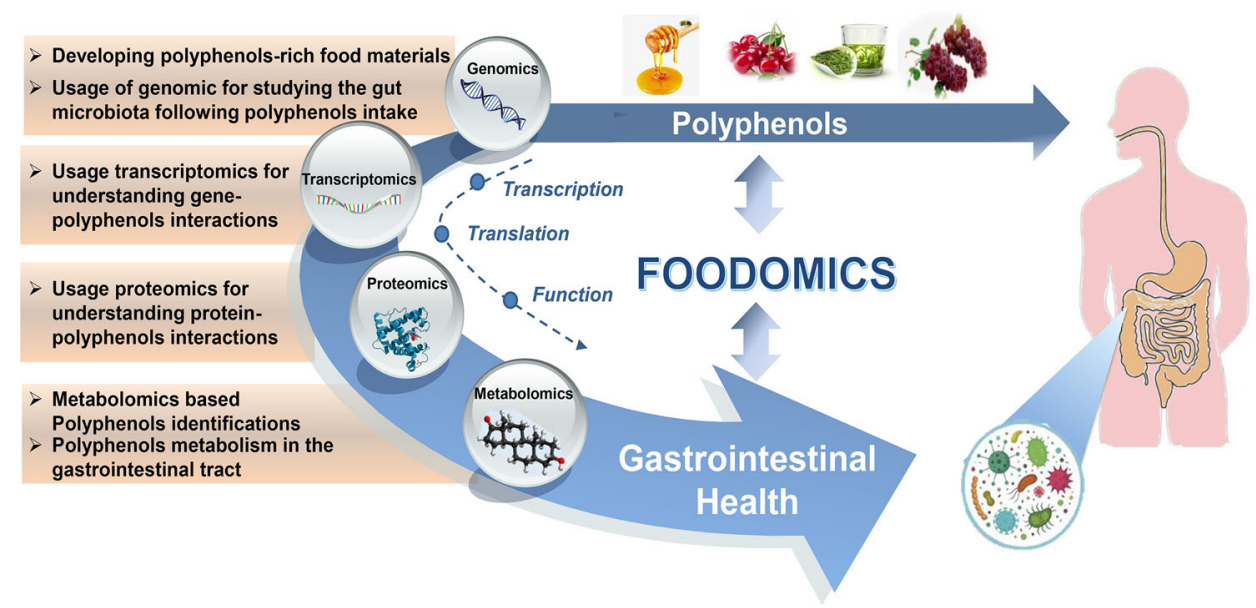

FIGURE 1 | Foodomics helps us understand the interplay between polyphenols, gut microbiota, and host health. Foodomics applies multiple high-throughput omics technologies to provide novel insights into gene transcription, protein expression, and dietary polyphenols metabolism that interact with gut microbiota and host health.

regulate gut microbiota by anti-microbial activity with bacteriostatic or bactericidal actions and serve as are potential prebiotics enhancing the growth of beneficial microbiota. In vitro and in vivo studies indicate that cocoa polyphenols supplements stimulate the population of beneficial bacteria, including Lactobacillus (34), Bifidobacterium (35), Prevotella, Faecalibacterium prausnitzii (36), Blautia (37), Bacteroides uniformis (38), and Lactobacillus reuteri (39). In turn, cocoa polyphenols supplements inhibited the growth of Escherichia coli (E. coli) enterohemorrhagic O157: H7, Salmonella typhimurium, Listeria monocytogenes (34), Bacteroides, Clostridium, Staphylococcus (40), Lactobacillus-Enterococcus group (37), and Clostridium histolyticum (36). Polyphenols from diverse grapes (mostly phenolic acids, flavonols, favan-3-ols, anthocyanins and hydroxybenzoates) (41) attenuated Clostridium histolyticum (42), Staphylococcus aureus, Pseudomonas aeruginosa, Klebsiella pneumoniae, E. coli, Staphylococcus epidermis, Enterococcus faecalis, Streptococcus pyogenes, Haemophilus influenzae, Enterococcus casilliflavus, and Pneumococcus (43), and increased the growth of Lactobacillus-Enterococcus (42), Lactobacillus acidophilus, Lactobacillus reuteri (44), Lactobacillus casei, Lactobacillus plantarum (45).

Colon cancer is one of the world's most prevalent tumor (46). The inhibition of colon cancer and colorectal cancer may be achieved by polyphenols and their metabolites owing to the inhibition of cancer cell proliferation (47), promoting cancer cell death (48), and regulating intestinal microbes. For instance, the potential of the date palm extract (Phoenix dactylifera L.), date polyphenol-rich extract and their metabolites SCFAs in Caco-2 cells was investigated, and both significantly increased the growth of bifidobacteria in human fecal batch cultures to enhance colon health and inhibit colon cancer cell growth (49). Berries are rich in polyphenols, and their inhibitory effects on colorectal cancer progression have been assessed by multiple in vitro studies (50). Cranberries polyphenols inhibit colorectal cancer mainly by regulating relevant gene expression, altering cellular signaling pathways, scavenging free radicals in cells, inhibiting cancer cell proliferation and promoting apoptosis (51). Using extracted and purified polyphenols from $P$. koraiensis pinecone (PPP), anti-proliferative activities against colon cancer cells were studied (52). The authors tested different ethanol concentrations $(20 \%, 40 \%$ and $60 \%)$ in the PPP extract and found the highest phenolic content $(57.25 \pm 1.83 \%)$ in PPP40 extract that showed the greatest inhibitory effect against LOVO cells. Apoptosis in LOVO cells caused by PPP-40 was mainly mediated through the activation of intrinsic and extrinsic caspase and mitochondria dysfunction (52).

IBD is a global disease characterized by a group of chronic and recurring inflammatory conditions in the GI tract (53). Several in vivo or in vitro experiments reported that different pathogenesis pathways have been linked to dietary polyphenols which had beneficial effects on the suppression and reduction of IBD symptoms (54). The natural polyphenol resveratrol identified in various plant species, has shown curative effects on IBD via the inhibition of NF- $\mathrm{KB}$ activation, decreased PGE 2 and PGD 2 levels, inhibition of neutrophil infiltration, as well as reducing COX-2 expression (55). Green tea polyphenols (GTPs) are rich in (-) epicatechin gallate (ECG), (-) epigallocatechin gallate (EGCG), (-) epicatechin (EC) and (-) epigallocatechin (EGC), all of which have a beneficial impact on attenuating IBD. The mechanism of GTP action includes promoted growth of Bacteroidetes microbiota, with increased SCFA production and down-regulating the inflammation-relating pathways (56).

\section{APPLICATION OF FOODOMICS AND INTEGRATION OF OMICS TOOLS IN FOOD SCIENCES}

Foodomics technologies have advanced rapidly in recent years, which is primarily reflected in existing technologies used in food 
science, making foodomics methodological research more flexible, as shown in Figure 2. Omics technologies mainly include genomics, transcriptomics, proteomics, and metabolomics (57), all of which apply multiple highthroughput omics technologies to investigate related issues in food science. Each omics technology have its own set of research goals, instruments, extraction \& separation technologies and data analysis tools. Foodomics helps in the analysis of the biological activities of foods and their potent compounds in order to gain new insights into important molecular mechanisms as well as the exploration and development of novel biomarkers. Foodomics also promotes human health by providing optimal tools to identify information on how dietary nutrition interacts with gene transcription, protein expression, and the metabolism (58). Understanding of foodomics technology is important for researchers to better understand the interactions between polyphenols and gut microbiota.

\section{Genomics}

Genomics refers to the sequencing, assembly and analysis of the structure and function of genomic genes within an organism. The primary goal of genomics is to comprehend the various components of biology and to obtain the maximum amount of genetic sequence knowledge as possible about biological components through experiments and calculations. Among the tools used in genomics, the most powerful and versatile ones are high-density arrays of oligonucleotides or complementary DNAs (cDNAs). DNA arrays are a collection of related DNA spots that represent single genes attached to a solid surface by covalent or electrostatic binding with suitable chemical matrices (59). Another powerful tool for studying the structure and function of the genome is the next-generation sequencing (NGS) technologies. Compared to DNA arrays, NGS technology is capable of processing millions of sequencing reactions simultaneously without requiring a sequence library (often referred to as massively parallel sequencing) (60). NGS enhances the speed of acquisition of DNA sequence information and reduces the sequencing costs (61). Single-molecule sequencing (also called third-generation sequencing systems) is likewise an attractive tool for studying genomics. Single-molecule sequencing, unlike NGS, encounters relatively simple orientation errors, and the sequencing samples are single DNA molecules that cannot be cloned or amplified during the preparation process (62). Single-molecule sequencing allows high-density single molecules expand asynchronously, thereby allowing highly flexible chemical kinetics (63).

Genomics provides opportunities for developing genetically modified crops and livestock with various advantages, including high growth performance, increased yield, disease/pest resistance, and improved nutrient levels in food materials. Genomics techniques enable the determination of the gene compositions of a single plant or farm animal. Based on the constructed "graphic genotype", plant breeders can find inheritable chromosome sections and accelerate the selection of marker traits, which may reduce the field labor required. Genomic techniques identify beneficial alleles in the genes that govern food properties and select more nutritious and safer crops

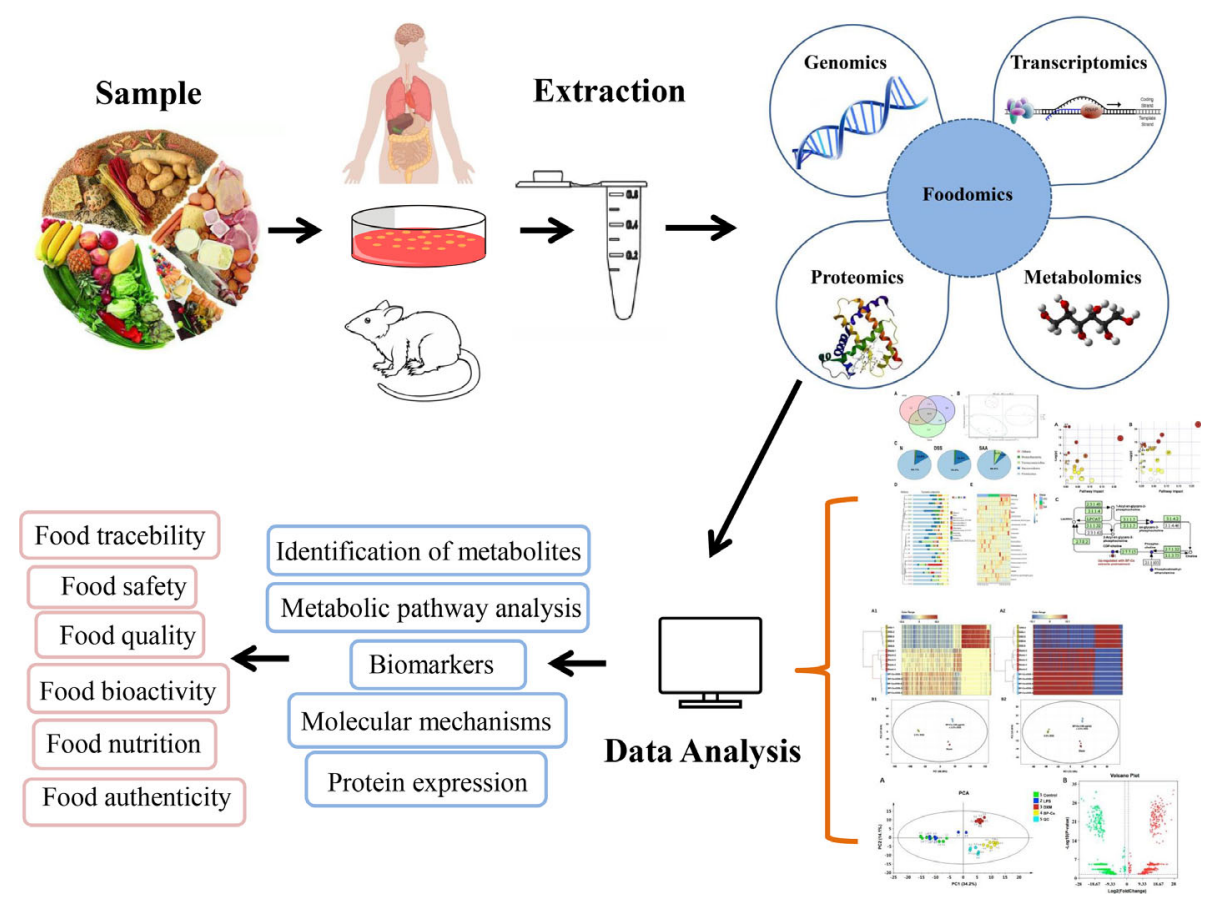

FIGURE 2 | Foodomics-application in food sciences. Research priorities and findings in food science are described intuitively in the form of visual data and graphs using foodomics technology. 
for better and healthier food (64). Moreover, efforts have been made in using genomics to assess the microorganisms in foods and manage food microbiological issues (65).

\section{Transcriptomics}

The transcriptome is the entire set of RNA transcripts produced by the genome, and it serves as a vital link between gene phenotype and DNA coding information (66). Transcriptomics is the study of all RNA information of a single cell or a group of cells, and it is a paramount tool for understanding the functional elements of the genome and revealing the molecular composition of cells (67). Transcription can be precisely measured through transcriptomics, allowing us to understand the extent and complexity of transcriptomes more comprehensively. Gene expression microarrays and large RNA sequencing (RNA-Seq) are the key methods for analyzing thousands of transcriptomics efficiently and quickly). Gene expression microarray technology was introduced in the 1990s and has since been widely used (68), allowing high-throughput research to advance. In recent years, gene expression microarray technology has been widely applied in the research of emerging diseases, production of new medicines, and the mechanism of food reaction.

The application of microarrays in gene expression are classified into two types according to their nature: microarrays on solid flat or microchip substrates and microarrays on cubic or particle substrates (69). Nevertheless, all samples are first tested to obtain the corresponding signal information, and the signals are subsequently processed with the processing method depending on the platform used. After processing, the relative expression level of each transcript from samples under different experimental conditions is calculated and analyzed to classify differentially expressing genes (70). However, there are several shortcomings in gene microarray analysis because it is based on known sequences, and it is thus impossible to characterize unknown RNA sequences. Consequently, a comprehensive and precise characterization of the transcriptome is impossible (66). RNA-seq however, can supplement this (71) allowing for qualitative and quantitative analysis of any kind of RNA, including microRNAs, messenger RNAs (mRNAs), small interfering RNAs (siRNAs), and long noncoding RNAs. RNAseq technology can be used for genome-wide high-throughput transcriptomics since it sequences the entire transcriptome (72).

Currently, transcriptomics technologies are widely applied in food crop production. Transcriptomic-based fingerprinting can be used to detect hazardous food constituents or contaminants, including dioxins, xenoestrogens, organochlorine pesticides, mycotoxins phytoestrogens, Maillard reaction products, and estrogen-like chemicals, allowing more effective control of food quality and safety (73). It also assist in elucidating the molecular mechanisms of metabolic transformations and functionalities in food fermentations (66), and demonstrate the effects of dietary nutrients from foods. Moreover, transcriptomics is used to study the alterations of host gene expression due to various dietary interventions. DNA microarray analysis of rats with on an energy restriction diet of $5-30 \%$ revealed 72 genes that underwent restriction level-dependent changes (74).

\section{Proteomics}

Proteomics is a complement to genomics and transcriptomics that offers precise biological knowledge for foodomics. The later refers to the use of proteomic techniques to analyze proteins in specific biological food systems on a wide scale. In addition to studying chemical structure and functional proteins, proteomics also investigate proteins alteration effects, quantitative analysis of protein abundance, protein interactions, and their intracellular mechanism exploration (75). Proteomics is dedicated to the qualitative and quantitative analysis of proteins expressed in biological systems at specific times and conditions (76). The procedures of proteomics includes the extraction and separation of proteins, protein digestion into peptides, mass spectrometric (MS) analysis, and then qualitative and quantitative analysis of proteins (77). In generally, there are two methods for protein isolation and separation in proteomics, namely two-dimensional electrophoresis (2-DE); or multi-dimensional liquid chromatography. The 2-DE method of protein isolation and separation is based on the isoelectric point (pI) and molecular mass separation of proteins by 2-DE on polyacrylamide gels, followed by image analysis to classify all discernible spots in the image to provide a reference for subsequent research (78).

The 2-DE process for extracting and separating proteins, on the other hand, has a lot of weaknesses. For example, the performance of the extraction and separation of high-molecular or low-molecular-weight proteins is poor and time-consuming (79). Therefore, multi-dimensional liquid chromatography has been developed, where protein extraction and separation is performed by LC coupled to tandem MS (LC-MS/MS). Currently, the tools used for proteomic analysis to characterize protein samples are MS (80), mainly including matrix-assisted laser desorption/ionization time of flight (MALDI-TOF) and electrospray ion trap (ESI-IT) MS. Both techniques first ionize proteins and then analyze them by MS (81). Proteomics research can be categorized as "bottom-up" or "top-down". In the "bottom-up" approach, purified protein or complex protein mixtures are first enzymatically digested from the corresponding protein into peptides, and then analyzed using MS (82). The "top-down" approach retains most unstable proteins that were destroyed in the "bottom-up" approach, and performs MS analysis on intact proteins without cleavage (83). Therefore, the "top-down" approach is more stable and reliable than the "bottom-up" approach.

These powerful proteomics methodologies had a major impact on the field of food science. Proteomics was applied in the quality control of various food of biological or transgenic origin using different high-performance separation techniques, combined with high-resolution MS (84). Using 2-DE, the proteomic map of Alfalfa (Medicago sativa) was established for the first time, and the protein pattern changes in different processes were studied (85). Proteomics was applied in animal production and health to separate and identify all proteins present in a given tissue or fluid, offering more specific methods for assessing meat maturation, characterizing the proteome changes of post-catch fish muscle, and establishing various production animals proteome maps (86). It is also 
adopted to identify microbial food contaminants and their toxins (87).

\section{Metabolomics}

The emergence and application of metabolomics is another milestone for foodomics studies. Metabolomics technology focuses on the qualitative and quantitative research of small molecule metabolites $(<1,000-1,500 \mathrm{Da})$, to compare the differences among samples (88). One of the main objectives of metabolomics research is to identify biomarkers, which are molecules that have a direct impact on an organism's metabolism or metabolic pathways. In general, metabolomics workflows include the following steps: extraction of target metabolites based on research goals; analytical instrument selection and sample preparation; sample on-board testing; collecting data; and using analytical tools for analysis and detection (89). Bioinformatics and chemometrics are analytical tools mainly used for metabolomics data (90).

There are two basic approaches targeted metabolomics and non-targeted metabolomics. Non-targeted metabolomics includes metabolic profiles and metabolic fingerprints (91), while targeted metabolomics is mainly used to analyze key metabolites on specific metabolic pathways, which can be used to investigate the key metabolic alterations caused by specific gene or protein changes. The scope of non-targeted metabolomics is relatively wide, with metabolic fingerprinting focused on comparing changes in metabolite patterns due to changes in internal or external factors (92). Metabolic profiling is focused on studying the differences in related metabolite levels and the effects of corresponding metabolic pathways, which have been applied for the identification of biomarkers in food and for the development of functional food.

The most frequently used data acquisition platforms in metabolomics are nuclear magnetic resonance (NMR), liquid chromatography-MS (LC-MS), gas chromatography-MS (GCMS), and capillary electrophoresis-MS (CE-MS) (93). Among them, the application of NMR technology was most common in early metabolomics studies. NMR is a powerful analytical technique, for quantifying metabolites and analyzing structural details. It needs small sample size and requires no complex sample preparation procedures such as sample separation or derivatization. However, NMR analysis technology has the limitation of relatively low sensitivity of metabolite detecting (94). MS-based metabolomics technologies have some advantages, and they are mainly used to identify unknown compounds and for quantitative analysis of metabolites (95). The significant advantages of MS analysis technology requiring a small sample volume, high sensitivity, and fast separation speed (96).

LC-MS is the most widely used among MS technologies. It can be applied in the majority of metabolic profiling studies and is a powerful technology that can quantify metabolites and accurately identify the structural information of metabolites. GC-MS technology focuses primarily on the analysis of volatile, non-polar and thermally stable compounds with high separation efficiency and excellent reproducibility, allowing it to analyze complex metabolic mixtures, and it is still extremely useful with the introduction of capillary gas chromatography (97). The appearance and application of CE-MS technology is a further supplement and improvement to LC-MS and GC-MS. CE-MS likewise requires minimal sample volume, and simple sample processing, high separation efficiency, while it exhibits excellent reproducibility and high sensitivity, and can be used to analyze highly polar or charged compounds (92). All these different omics techniques each have their own advantages, and combining several metabolomics analysis technologies will yield complementary analysis results.

Metabolomics technologies have been widely applied in food science. The usage of NMR-based metabolomics in functional food studies aided in the evaluation and characterization of active ingredients as well as the effects of various biomarkers in corresponding diseases (98). Metabolomic-based approaches combining non-targeted and targeted technologies can be applied in food quality testing, detecting chemical contaminants, evaluating food authenticity and assessing food quality (99). MS-based metabolomics were used for food traceability, which accurately determines the basic composition and origin of foods during various processes of manufacturing. Metabolomics may also be used to monitor changes in the metabolomic profiles and identify specific compounds as markers of food degradation (100). It is also used in nutritional epidemiology to identify biomarkers of dietary intake. The earliest biomarker identified using metabolomics after meat intake was trimethylamine $\mathrm{N}$-oxide (TMAO); 1-methylhistidineas was later confirmed as a biomarker of meat consumption (101).

\section{Integrating Approaches in Foodomics Studies}

Foodomics can be used not only for data collection by omic techniques, but also to integrate multiple omic techniques for getting more comprehensive and systematic experimental data (102). Foodomics technologies include chemometrics, epigenomics, bioinformatics and integration approaches. Chemometrics employs mathematical, statistical, and other formal logic-based methods to plan or select optimal measurement procedures and experiments, as well as to analyze chemical data to provide the most important chemical details (103). Chemometrics technology is a subset of metabolomics that involves building a model to define and validate target samples. The methods of identification and classification used in chemometrics technology mainly include unsupervised principal component analysis (PCA), supervised discriminant analysis (DA), hierarchical cluster analysis (HCA), and soft independent modeling of class analog (SIMCA) (104).

The term "epigenetic" simply means "in addition to genetic sequence changes". The term has evolved to refer to any mechanism that alters gene activity without altering the DNA sequence, resulting in changes that can be passed on to daughter cells (although experiments show that some epigenetic changes can be reversed (105). Epigenetics analysis is a fascinating research area of foodomics that involves analyzing changes in epigenetic status across the entire genome (106). Whole genome research is mainly used to investigate changes in chromosome structure, as chromosome structure can affect gene expression and thus the epigenetic status of the corresponding location (107). 
Bioinformatics is a technology for reprocessing and analyzing data obtained from various omics technologies. Bioinformatics utilizes a variety of tools to conduct in-depth exploration of data, and to ultimately identify biological significance through functional annotation, genetic and protein data cluster analysis. Biomarkers can be identified and molecular mechanisms can be explained based on bioinformatics, biostatistics and pathway analysis results (108). Integrating multi-omics approaches is necessary due to the unpredictability of the human body and its potential interactions with food. Using multi-omics platform enables researchers to obtain a comprehensive understanding on dietary food components and biological actions in the body.

\section{USING FOODOMICS TO CLARIFY GI PROTECTIVE MECHANISMS OF POLYPHENOLS}

A reliable approach is to integrate foodomics to clarify the GI protective effects of polyphenols with high-throughput molecular technologies that drive it. For genomics, transcriptomics, proteomics and metabolomics studies, foodomics is based on a combination of several analytical platforms and data processing. These omics technologies allow the identification of bioactive compounds of polyphenols and determination of changes induced by polyphenols at the molecular level.

\section{Identification of Plant Derived Bioactive Polyphenols Using Foodomics}

Due to the high complexity of plant polyphenols, the analysis of polyphenols from plant extracts or biological samples has numerous known difficulties in various analytical procedures. Qualitative and quantitative analysis and data processing are two specific bottlenecks of polyphenolics analysis. Foodomics has introduced novel concepts and advanced technologies for identifying bioactive compounds (109). As a result, advanced foodomics technologies were used to improve the analytical methods of polyphenol compounds. We summarized typical examples of using foodomics approaches to analyze the plant derived polyphenols active compounds in fruits (Table 1-1), drinks (Table 1-2), grain and oil (Table 1-3) and other natural products (Table 1-4).

For the application of foodomics technology in understanding the GI protective effects of polyphenols, we provides an overview of recent studies, on polyphenols or polyphenol-rich foods, the foodomics technology applied (genomics in Table 2-1, transcriptomics and protemics in Table 2-2, metabolomics and multi-omics in Table 2-3), experimental model and dosage, and major findings.

\section{Gene-Based Genomics and Transcriptomics to Investigate GI Protective Mechanisms of Polyphenols}

Foodomics technologies accurately analyze polyphenol compounds in both qualitative and quantitative aspects. Moreover, gene-based genomics and transcriptomics can be used to study the interaction between polyphenols and the GI tract. Owing to continuous optimization of gene-level research technology, gene expression microarray technology has developed as a crucial analytical technology in the transcriptomics field to investigate the interactions between genes following intake of bioactive constituents from food (159). Alberto et al. applied gene expression microarray technology to investigate the effect of polyphenols from enriched extract of rosemary on two colon adenocarcinoma cell lines. Differences in the G2/M arrest inhibition were found in the two colon adenocarcinoma cell lines after treatment with an enriched extract of rosemary. Rosemary polyphenols induced a low degree of apoptosis in colon adenocarcinoma cell lines and the results also indicated multiple other signaling mechanisms that may lead to apoptosis of colon cancer cells (160).

Dolara et al. (141) used transcriptomics to investigate 5,707 expressed genes to further determine the molecular effects of wine polyphenols on colonic mucosa in F344 rats. Wine polyphenols may protect the colonic mucosa by improving intestinal function and having anti-colonic cancer activities by reducing oxidative damage, modulating the colonic microbiota and down-regulating the expression of genes involved in metabolism, transport, signal transduction and intercellular signaling. Wang et al. (161) evaluated the interaction of green tea polyphenols (GTPs) and gut microbiota through transcriptomics. In that study, Female Sprague-Dawley (SD) rats were treated with GTP for 6 months. $16 \mathrm{~S}$ ribosomal RNA (rRNA) amplicon sequencing (16S-seq) and Shotgun metagenomic community sequencing (SMC-seq) were then used to determine the effect of GTP on the intestine microbiota and the possible connection between improvements in and the beneficial effects of GTP. The SD rats that were treated with GTP over long time periods exhibited a dose-dependent modification of Bacteroides and genes related to energy metabolism, which proved to be beneficial for weight control and maintenance. Yang et al. (162) studied the inhibitory effect of combined polyphenols on colitis-related carcinogenesis (CRC) in mice by the $16 \mathrm{~S}$ rRNA gene sequence. The data show that the gut microbiota plays a key role in the treatment of CRC, bound polyphenol of the inner shell treated altering the diversity and overall structure of the microbiota in tumor-bearing mice, and also exerts a regulatory effect on 17 signaling pathways involved in related genes.

\section{Protein-Based Proteomics to Investigate GI Protective Mechanisms of Polyphenols}

Proteomics is employed to further the understanding of the relationship between the GI tract and polyphenols at the protein level. It assesses the functional protein changes of probiotics in the gastrointestinal transit, metabolic processes using different protein identification approaches by studying the beneficial effects of probiotics on the gastrointestinal tract and the mechanism of action (163). Proteomics is mainly based on MS technology, and it focuses on obtaining functional information about the interaction of polyphenols with the GI tract and related pathway by assessing protein expression changes. Valdés et al. 
TABLE 1-1 | MS-based foodomics applied to the determination of polyphenolic active compounds in fruits.

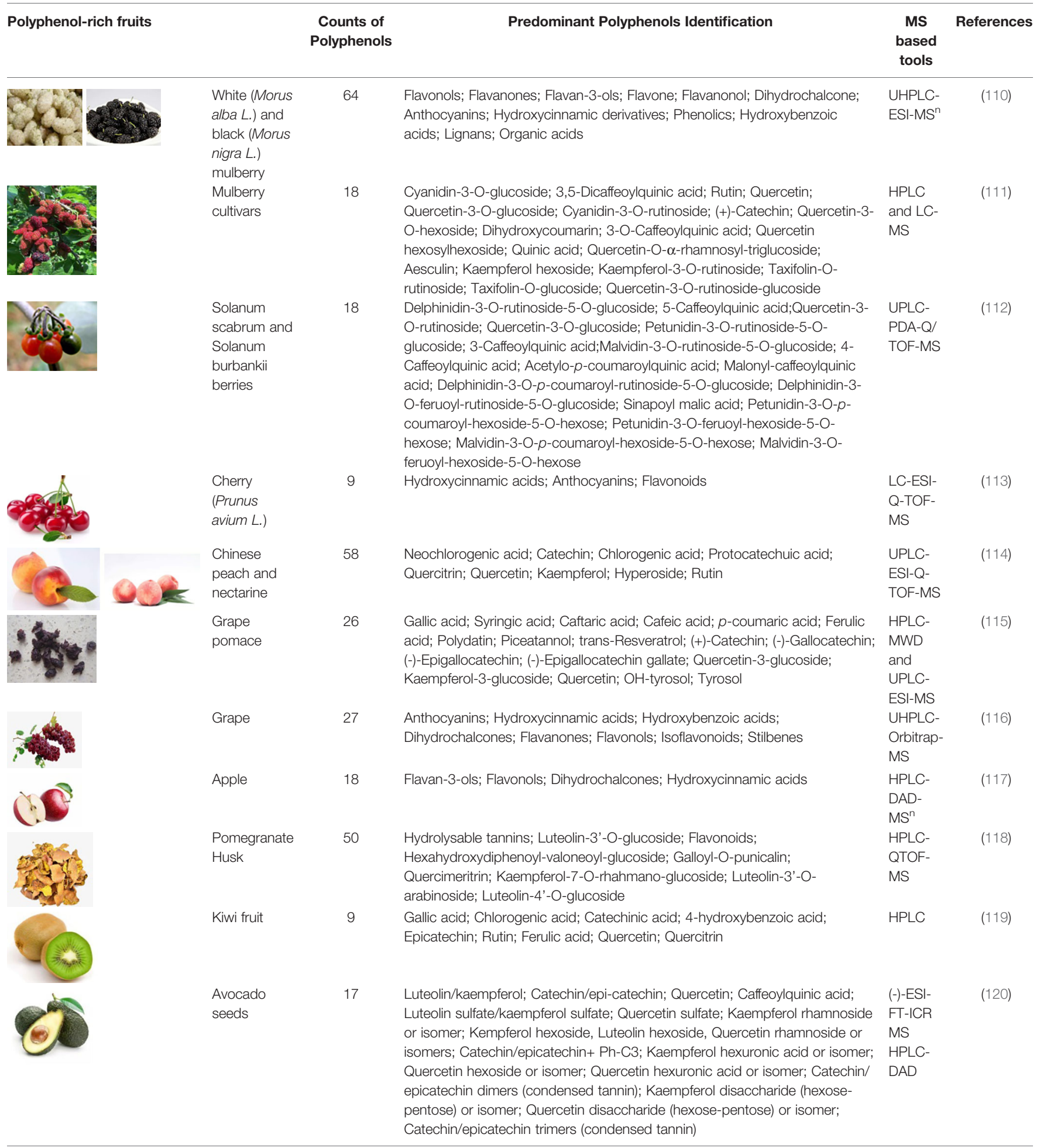

(164) used a proteomics strategy to explore the effect of polyphenol-rich rosemary extract at various concentrations on HT-29 human colon cancer cells for 2, 6 and 24 hours. Nanoliquid chromatography-tandem mass spectrometry (nano-LCMS/MS) was combined with stable isotope dimethyl labeling
(DML) technology to quantitatively examine relative changes in the protein. Rosemary extract, which is rich in polyphenols protected intestinal health with anti-proliferative effects by inducing proteomic changes in cells of HT-29 colon cancer, reducing aggregates formation and stimulating autophagy. 
TABLE 1-2 | MS-based foodomics applied to the determination of polyphenolic active compounds in grain and oil.

\begin{tabular}{|c|c|c|c|c|c|}
\hline Polyphenol-rich & Drinks & $\begin{array}{l}\text { Counts of } \\
\text { Polyphenols }\end{array}$ & Predominant Polyphenols Identification & $\begin{array}{c}\text { MS } \\
\text { based } \\
\text { tools }\end{array}$ & References \\
\hline & Red wine & 43 & $\begin{array}{l}\text { Procyanidin trimer type B isomer; Gallic acid; Protocatechuic acid-O-hexoside; Gentisic acid; } \\
\text { Protocatechuic acid; Caftaric acid; Catechin; Caffeic acid-C-hexoside; Coumaric-O-hexoside; p- } \\
\text { hydroxybenzoic acid; Caffeic acid; Peonidin-3-O-glucoside; Malvidin-3-O-glucoside; Resveratrol; } \\
\text { Cyanidin-O-dihexoside; Quercetin-O-rhamanoside; Epicatechin; Eriodictyol-O-hexoside; } \\
\text { Petunidin; Delphinidin-O-dihexoside; Coumaric acid; Myricetin-O-hexoside; Cyanidin; } \\
\text { Kaempferol-3-O-rutinoside; Ferulic acid; Piceid acid isomer; Epicatechin-O-gallate; Naringenin; } \\
\text { Kaempferol-3-O-glucoside; Quercetin; Quercetin-O-hexoside; Delphinidin; Delphinidin-O- } \\
\text { hexoside; Cyanidin-O-hexoside; Petunidin-O-hexoside; Delphinidin acetyl hexoside }\end{array}$ & $\begin{array}{l}\text { HPLC- } \\
\text { ESI- } \\
\text { LTQ- } \\
\text { Orbitrap- } \\
\text { MS }\end{array}$ & $(121)$ \\
\hline & Beer & 47 & $\begin{array}{l}\text { Phenolic acids; Hydroxycinnamoylquinics; Flavanols; Flavonols; Alkylmethoxyphenols; Alpha-and } \\
\text { Iso-alpha-acids; Flavones; Hydroxyphenylacetic acids; Prenylflavanoids; Feruloylquinic acid; } \\
\text { Caffeic acid-O-hexoside; Coumaric acid-O-hexoside; Sinapic acid-O-hexoside; catechin-O- } \\
\text { dihexoside; kaempferol-O-hexoside; apigenin-C-hexoside-pentoside }\end{array}$ & $\begin{array}{l}\text { LC-ESI- } \\
\text { LTQ- } \\
\text { Orbitrap- } \\
\text { MS }\end{array}$ & $(122)$ \\
\hline & Green tea & 86 & $\begin{array}{l}\text { Phenolic acids; PAs; Flavan-3-ols and their derivatives; Monomeric hydrolyzable tannins; Flavonol } \\
\text { and flavonol glycosides; Flavone glycosides }\end{array}$ & LC-MS & $(123)$ \\
\hline & Coffee & 11 & $\begin{array}{l}\text { Gallic acid; DHB; Caffeine; Chlorogenic acid; p-Coumaric acid; trans-Ferulic acid; Rutin; Naringin; } \\
\text { Resveratrol; Quercetin; Kaempferol }\end{array}$ & $\begin{array}{l}\text { CLC- } \\
\text { DAD } \\
\text { and LC- } \\
\text { MS/MS }\end{array}$ & (124) \\
\hline & $\begin{array}{l}\text { Malaysian } \\
\text { cocoa } \\
\text { powder }\end{array}$ & 5 & Catechin; Epicatechin; Gallic acid; Protocatechehuic acid; Chlorogenic acid & $\begin{array}{l}\text { HPLC- } \\
\text { UV-ESI- } \\
\text { MS/MS }\end{array}$ & $(125)$ \\
\hline
\end{tabular}

Barnett et al. (165) used transcriptomics and proteomics to assess the effect of dietary intake of green tea extract rich in polyphenols (GrTP) on human colon IBD. They used 2-DE and LC-MS technologies to investigate gene expression in the colon and protein expression changes in the Mdr1a ${ }^{-/-}$mouse as an in vivo model of humans. GrTP reduced intestinal inflammation in the colon of the mouse model of IBD. Li et al. (166) investigated the inhibitory effect and anti-bacterial activity of catechin on Escherichia coli O157:H7 cell lines in vitro and in simulated human gastrointestinal environment by proteomics. The changes in protein expression were studied by 2-DE that showed changes in the expression of 34 proteins in the bacterial proteome, of which 2 were up-regulated, 12 were down-regulated and 20 were lost. It was shown that catechin had an inhibitory effect on EHEC O157:H7, and the specific mechanism of action must be studied in conjunction with in vivo studies.

\section{Metabolomics Based on Microbial/Colonic Metabolic Metabolites to Investigate GI Protective Mechanisms of Polyphenols}

Several researchers have highlighted metabolomics as an important future direction of foodomics, owing to its ability to characterize related biological functions and phenotypes (167). Metabolomics are likewise a suitable omics technology to target the metabolic pathway and understand molecular mechanisms of the metabolism. Metabolomics technology has been used in studies investigating the interaction of polyphenols with the GI tract through changes in the detection of small molecule metabolites. Fernández-Arroyo et al. (168) used nano LC-ESI-
TOF-MS to study the anti-proliferative effects of phenolic compounds extracted from extra-virgin olive oil in treating SW480 and HT29 human colon cancer cell line. The analysis of cytosol and cytoplasmic metabolites revealed the presence of numerous phenolic compounds and their metabolites, mainly quercetin and oleuropein aglycones (and their derivatives), in SW480 and HT29 cell lines, which in turn affect cell signaling pathways and lead to apoptosis. Li et al. (169) used UPLC-QTOF/MS metabolomics to investigate in vitro GI defensive effects of polyphenol-rich bee pollen (BP) extracts on the dysfunction of the Caco-2 intestinal barrier induced by dextran sulfate sodium (DSS). Throughout the early stages of DSS-induced colitis, findings revealed that BP had significant therapeutic ability. The metabolomic results indicate that BP and DSS-treated Caco-2 cell metabolites are significantly different compared with the blank-treated group, and the metabolic pathways involved had the largest effect on the glycerophospholipid metabolic pathway, indicating that BP treatment suppressed the inflammatory response by regulating the cells' own metabolites and metabolic pathways.

Di Nunzio et al. (170) combined proteomics and transcriptomics technologies to investigate the changes in the distal colon mucosa of F344 rats evoked by dietary quercetin. Dietary quercetin in the distal colon mucosa had an inhibitory effect on colorectal cancer by enhancing expression of tumor suppressor genes, cell cycle inhibitors, genes involved in xenobiotic metabolism and enhancing the inhibitory effect on the MAPK pathway. To investigate the anti-proliferative effects of dietary polyphenols on HT-29 human colon cancer cells, Ibánez et al. (171) developed a multiplatform analysis that 
TABLE 1-3 | MS-based foodomics applied to the determination of polyphenolic active compounds in grain and oil.

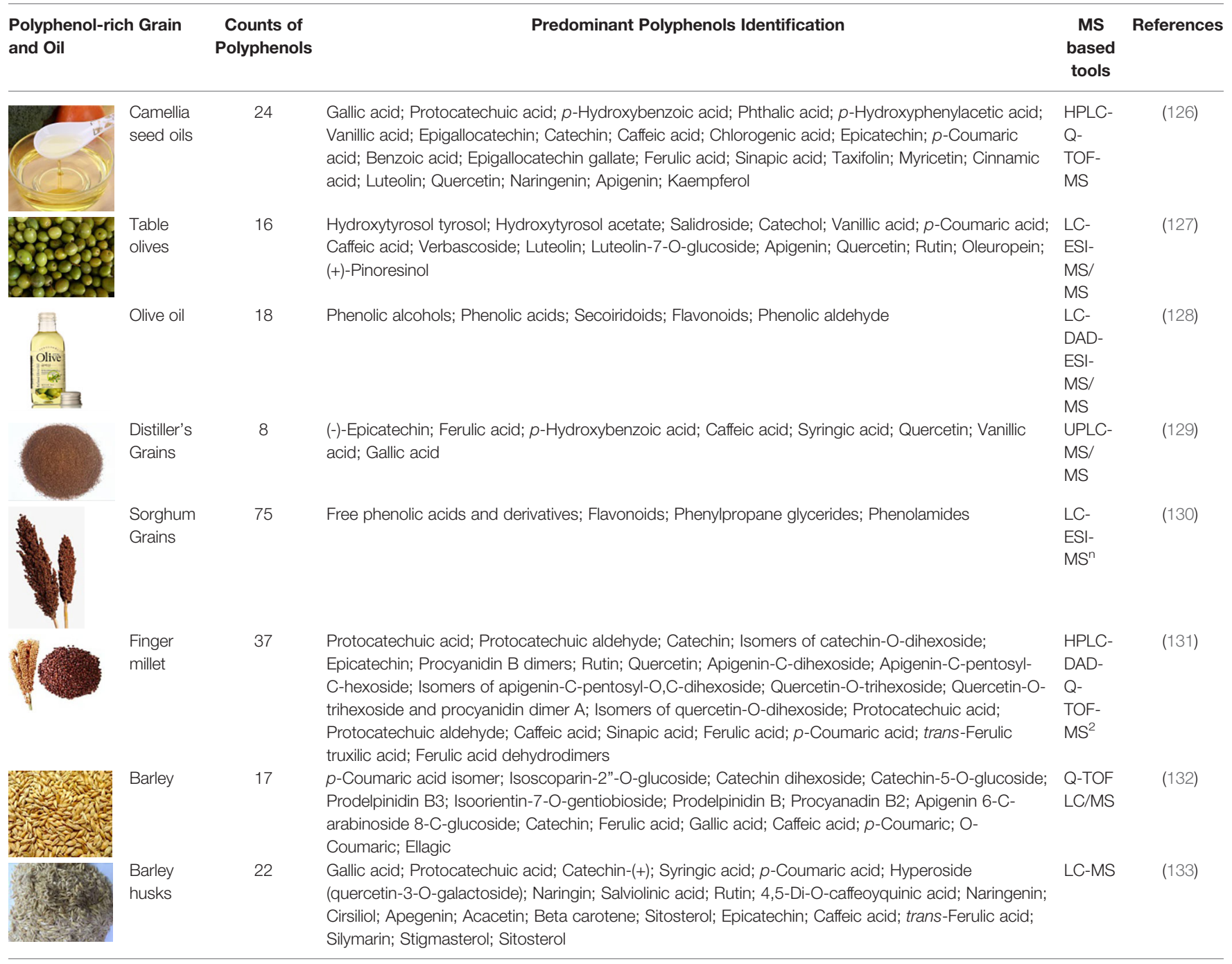

combined CE, RP/UPLC, and HILIC/UPLC, both coupled to TOF-MS for metabolomics analysis. Their findings revealed that dietary polyphenol treatment altered 22 closely related metabolites in HT-29 cells, which has the potential to for inhibit colon cancer.

\section{Multiple Omics Platforms for Understanding the Protective Effects of Polyphenols Against GI Disorders}

With the technological development of foodomics, food science studies based on data generated from sequencing approaches and combining two or more technologies ("multi-omics") are considered as more reliable, which also allows for integrating system-level approaches. The multi-omics approach has a more comprehensive and systematic analysis capability, which is more conducive for in-depth investigation of complex issues in food science. Dietary polyphenol interventions for GI disorders involve multiple molecular and biochemical mechanisms during the process of biotransformation and absorption. Integrated multi-omics analysis is necessary to obtain comprehensive omics-data to identify the genes, proteins and metabolites involved in metabolic regulation, and further construct metabolic pathways to comprehensively analyze the mechanism of polyphenols for gastrointestinal protection, and further elucidate the complex network of interactions between the dietary polyphenol, GI tract, and host (156). Mayta-Apaza et al. confirmed that polyphenol-rich tart cherries regulate intestinal health by increasing the quantity of beneficial microbiota in the human colon. To determine how gut microbiota were influenced by polyphenol metabolites from polyphenol-rich tart cherries in the human colon, they authors conducted bacterial fermentation assays on polyphenol-rich tart cherry concentrate juices and pure polyphenols (and apricots) in vitro and assessed the results based on $16 \mathrm{~S}$ rRNA gene sequence and metabolomics. In vitro, gut microbiota metabolized polyphenols into 4-hydroxyphenylpropionic acids and tart cherries modulate the increase of Bacteroides. In vivo data showed decreased Bifidobacterium, Bacteroides, and increased levels of Collinsella, Lachnospiraceae, Ruminococcus in individuals with high 
TABLE 1-4 | MS-based foodomics applied to the determination of polyphenolic active compounds in other natural products.

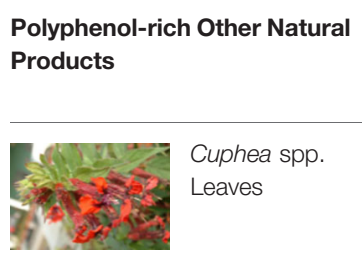

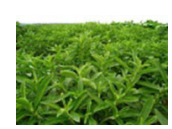

Stevia

rebaudiana

leaves

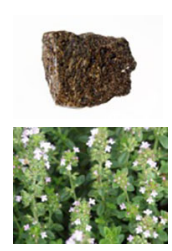

Chinese

propolis

Thymus $\mathrm{x}$

citriodorus

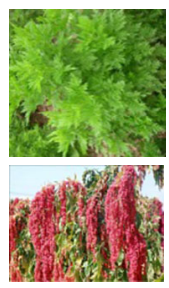

Folium

Artemisiae

Argyi

Djulis

(Chenopodium

formosanum

Koidz.)

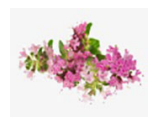

Thymus

schimperi

Ronniger

Polyphenols

Predominant Polyphenols Identification

ESI-Q-

TOF

arabinoside; Rutin; Kaempferitrin; Kaempferol-galloyl-glucoside; Kaempferol 7-rhamnoside

Kaempferol-3-O-rutinoside; Kaempferol-3-xyloside; Kaempferol-3-glucuronide; Quercetin-

acetyl-glucuronide;

55 Phenol diglycoside; Caffeoyl quinic acids; Caffeoyl shikimoyl hexose isomers; Caffeoyl shikimic acids; Feruloyl quinic acid; Dicaffeoyl quinic acid isomers; Kaempferol caffeoyl rutinoside Flavonols glycosides; Kaempferol-3-O-hexoside; Quercetin caffeoyl rutinoside; Quercetin dimethylether-3-O-hexoside; Quercetin3-O-deoxyhexoside; Apigenin7-O-

hexoside; Kaempferol-3-O-pentosyl deoxyhexoside; Dicaffeoyl quinic acid isomer;

Kaempferol 7-O-deoxyhexoside

11 Gallic acid; Chlorogenic acid; Caffeic acid; (+)-Catechin; p-Coumaric acid; (-)-Epicatechin;

Taxifolin; Myricetin; Luteolin; Quercetin; Ferulicacid

Eriodictyol-di-O-hexoside; 5'-Hydroxyjasmonic acid 5'-O-hexoside; Eriodictyol-O-hexoside; Quercetagetin dimethyl ether O-hexoside; Eriodictyol-O-hexoside; Luteolin-5- $\beta$-O-glucoside; Naringenin-O-hexoside; Eriodictyol-O-hexuronide; Luteolin-7- $\alpha$-O-glucuronide; Luteolin-7-O-

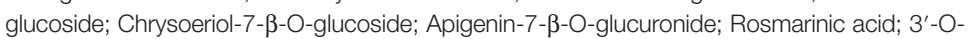
(8"-Z-Caffeoyl) rosmarinic acid

Q-

Orbitrap-

MS/MS

22 Vanillic acid; Quercetin-acetyl-rutinoside; Quinic acid; Hydroxyphenylacetic acid; Caffeoylputrescine; Hydroxyphenylacetic acid pentoside; Vanillic acid hexoside; Quercetin-acetylrutinoside hexoside; Rutin; Rutin-O-pentoside;Quercetin-3-O-(coumaroyl)-rutinoside; Quercetin-3-O-(coumaroyl)-rutinoside pentoside; Quercetin-3-O-(coumaroyl)-rutinoside deoxyhexoside; Quercetin-acetyl-rutinoside hexoside Glucuronide; Caffeoyl-spermine-

conjugate; Querctin-acetyl-glycoside

23

Eriodictyol; Luteolin-7-O-glucoside; (Epi) gallocatechin; Luteolin-7-O-glucoronide; Luteolin-4'O-(rhamnosyl) glucoside; Luteolin-6-C-pentoside-8-C-hexoside; Luteolin-6-C-glucoside; Chryseoriol-7-O-glucoside; Apigenin-7-O-(acetyl-apiosyl) glucoside; Luteolin-7-O-(2' '-apiosyl-acetyl)glucoside; Luteolin-6-C-pentoside; Salvianolic acid A; Dihydroxytrimethoxy flavone; Luteolin-7-O-(acetyl-apiosyl) xyloside; Luteolin-7-O-(dipentosyl) glucuronide; Luteolin-7-O-glucuronide-3'-O-glucoside; Luteolin; Trihydroxy-dimethoxyflavone; Hydroxytetramethoxyflavone; Hydroxy-trimethoxyflavone; Hydroxy-trimethoxyflavone isomer; Trihydroxy-trimethoxyflavone; Hispidulin
HPLC-

DAD-

ESI-MS/

MS

HPLC-

ESI-MS/

MS
MS

based

tools

UHPLC

using

References

(134)

UHPLC-

(135).

QqTOF-

MS/MS

LC-MS/

HPLC-

ESI-MS/

$M^{n}$

NMR

UHPLC-
Bacteroides. Low Bacteroides individuals had decreased Collinsella, Lachnospiraceae, Ruminococcus, while Bacteroides, Prevotella, Bifidobacterium levels increased (157).

Ibánez et al. applied transcriptomics, proteomics, and metabolomics on mutiple platforms (microarray analysis, MALDI-TOF/TOF-MS and CE/LC-MS) to examine the antiproliferation effect of polyphenols extracted from rosemary on the total gene, protein and metabolite expression in human HT29 colon cancer cells. The results demonstrated that the dietary polyphenols from rosemary are effective in inhibiting HT29 colon cancer cell growth and proliferation (172). Zhou et al. investigated the effect of GTPs on the metabolic regulation of gut microbiota in SD rats, and analyzed the key metabolites in rat intestinal contents by GC-MS metabolomics and HPLC metabolic methods. They found that GTPs treatment reduced the level of caloric carbohydrates and regulated the metabolism of bile acids, fatty acids and amino acids metabolized by gut microbiota (173). To examine the metabolites present in the gut microbiota-dependent mitochondrial tricarboxylic acid (TCA) cycle and urea cycle of GTPs, 16S rRNA gene sequencing and hydrophilic interaction liquid chromatography (HILIC)-heated electrospray ionization (HESI)-tandem liquid chromatogram mass spectrometry (LC-MS) were used (174). They found that GTPs enhanced the energy conversion and maintained gut health by increasing the mitochondrial TCA cycle and intestinal microbiota urea cycle in rats.

\section{CONCLUSIONS AND FUTURE PERSPECTIVES}

Polyphenols are particularly complex and ubiquitous components of our daily foods sourced from plants, vegetables and fruits. It has shown potential for prevention and treatment of 
TABLE 2-1 | Genomics in understanding the Gl protective effects by polyphenols and polyphenolic-rich foods.

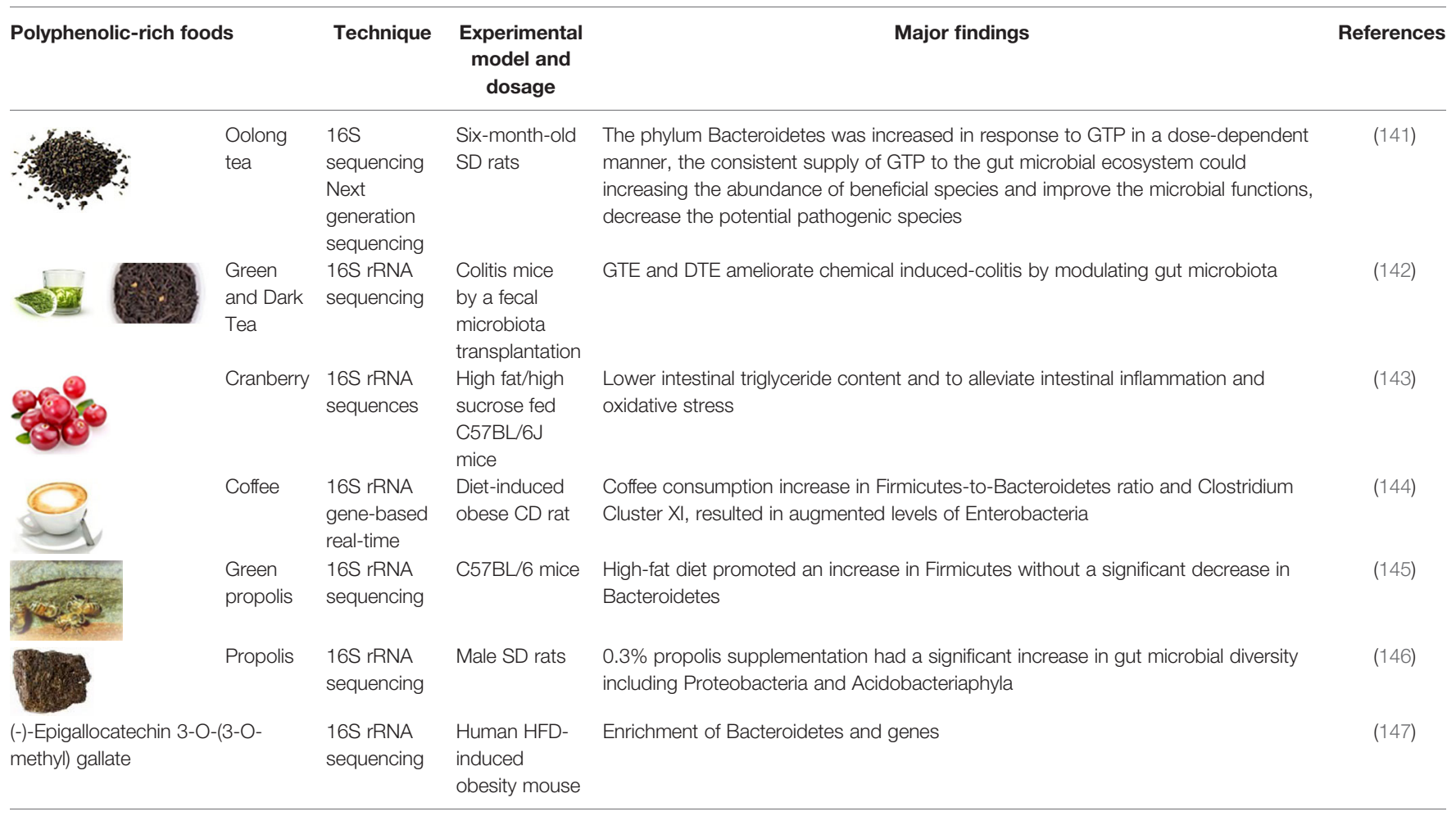

GI disorders, and the interactions between polyphenols and gut microbiota have gained significant attention due to their relevance to bioavailability and host health. Latest advancement of innovations in foodomics have significantly accelerated our understanding of food science and allowed a more comprehensive understanding at the molecular level of the interactions between polyphenols and the GI tract. However, while awareness of the
polyphenol-GI tract relationship is growing, there is still a long way to go. There are evident shortcomings and limitations of the interactions between polyphenols and the GI tract. The majority of polyphenols in the natural food matrix are in the form of bound polyphenols that cannot be directly metabolized. As xenobiotics in the GI tract, polyphenols must be metabolized and transformed by the gut microbiota in the colon before they

TABLE 2-2 | Transcriptomics and Proteomics in understanding the Gl protective effects by polyphenols and polyphenolic-rich foods.

\begin{tabular}{|c|c|c|c|c|c|}
\hline \multicolumn{2}{|c|}{ Polyphenolic-rich foods } & \multirow{2}{*}{$\begin{array}{l}\text { Technique } \\
\text { 2D-DIGE }\end{array}$} & \multirow{2}{*}{$\begin{array}{l}\begin{array}{c}\text { Experimental model } \\
\text { and dosage }\end{array} \\
\text { Cellular models (Caco-2, } \\
\text { Caco-2/HT-29-MTX, and } \\
\text { THP-1) of the intestinal } \\
\text { epithelium }\end{array}$} & \multirow{2}{*}{$\begin{array}{l}\text { Major findings } \\
\text { n different strengths of response, the Kale digesta } \\
\text { mpact on different important antioxidant enzymes }\end{array}$} & \multirow{2}{*}{ References } \\
\hline & $\begin{array}{l}\text { Plums and } \\
\text { cabbages }\end{array}$ & & & & \\
\hline & Oolong tea & $\begin{array}{l}\text { Microarrays } \\
\text { Two- } \\
\text { dimensional } \\
\text { gel } \\
\text { electrophoresis } \\
\text { LC-MS }\end{array}$ & $\begin{array}{l}\text { Multidrug resistance } \\
\text { targeted mutation } \\
\text { (Mdr1a-/-) mice }\end{array}$ & $\begin{array}{l}\text { GrTP can ameliorate inflammation in the colon of the Mdr1a-/- mouse model } \\
\text { of IBD }\end{array}$ & $(110)$ \\
\hline & $\begin{array}{l}\text { Chokeberry } \\
\text { juice }\end{array}$ & $\begin{array}{l}\text { Gene } \\
\text { expression } \\
\text { microarray } \\
\text { analyses }\end{array}$ & $\begin{array}{l}\text { Human model of colon } \\
\text { cancer Caco-2 cells }\end{array}$ & $\begin{array}{l}\text { Exposure of Caco- } 2 \text { cells to pre-digested chokeberry juice resulted in inhibition } \\
\text { of both cell proliferation and viability }\end{array}$ & $(149)$ \\
\hline & Sugarcane & LC-MS/MS & $\begin{array}{l}\text { LPS-stimulated SW480 } \\
\text { colon cancer cells }\end{array}$ & $\begin{array}{l}\text { up regulation of the oxidative stress mediator SELH, suppress the } \\
\text { phosphorylation of NFKB and inhibit secretion of the pro-inflammatory cytokine } \\
\text { IL-8. and contributes to the regulation of important signaling proteins including } \\
\text { PKA, PKC } \beta \text {, c-Jun, EGFR and SIRT1 }\end{array}$ & $(150)$ \\
\hline Quercetin & & $\begin{array}{l}\text { MALDI-FT-MS } \\
\text { MALDI-TOF/ } \\
\text { TOF-MS }\end{array}$ & Male inbred F344 rats & The changes evoked by quercetin can inhibit colorectal cancer & $(151)$ \\
\hline
\end{tabular}


TABLE 2-3 | Metabolomics and multi-omics in understanding the Gl protective effects by polyphenols and polyphenolic-rich foods.

\begin{tabular}{|c|c|c|c|c|c|}
\hline & $\begin{array}{l}\text { Polyphenolic- } \\
\text { rich foods }\end{array}$ & Technique & $\begin{array}{l}\text { Experimental model and } \\
\text { dosage }\end{array}$ & Major findings & References \\
\hline If & $\begin{array}{l}\text { Red wine and } \\
\text { grape juice }\end{array}$ & ${ }^{1} \mathrm{H}-\mathrm{NMR}$ & $\begin{array}{l}31 \text { men and } 22 \text { women; } \\
\text { mean SD age } 57.6 \pm 1.3 \\
\text { years; mildly hypertensive; } \\
\text { non-smokers }\end{array}$ & $\begin{array}{l}\text { The mixture of grape juice and wine extract induced a reduction } \\
\text { in isobutyrate, indicate that polyphenols are able to modulate the } \\
\text { microbial ecology of the gut }\end{array}$ & $(152)$ \\
\hline 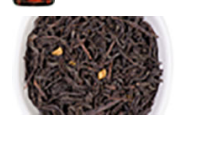 & $\begin{array}{l}\text { Black tea } \\
\text { extract and red } \\
\text { wine/grape } \\
\text { juice extract }\end{array}$ & $\begin{array}{l}{ }^{1} \mathrm{H}-\mathrm{NMR} \\
\text { GC-MS } \\
\text { LC-MS }\end{array}$ & Five-stage in vitro Gl model & BTE and RWGE modulate microbial SCFA production & $(153)$ \\
\hline wa & Pomegranate & $\begin{array}{l}\text { UPLC-ESI- } \\
\text { QTOF-MS/MS }\end{array}$ & $\begin{array}{l}\text { Colorectal cancer }(\mathrm{CRC}) \\
\text { patients }\end{array}$ & High punicalagin content hampered urolithins formation & $(154)$ \\
\hline & Apple & $\begin{array}{l}\text { 16S rRNA gene } \\
\text { sequencing } \\
\text { Mass } \\
\text { spectrometry } \\
\text { Gas } \\
\text { chromatography } \\
\text { time-of-flight } \\
\text { mass } \\
\text { spectrometry }\end{array}$ & SD rats & $\begin{array}{l}127 \text { proteins were differentially expressed and resulted in } 123 \\
\text { fecal metabolites; there was a strong negative linear relationship } \\
\text { between the relative abundance Firmicutes and Bacteroidetes in } \\
\text { the high-fat group }\end{array}$ & $(155)$ \\
\hline & Tart cherries & $\begin{array}{l}16 S \text { rRNA gene } \\
\text { sequencing LC/ } \\
\text { MS }\end{array}$ & $\begin{array}{l}\text { In vitro incubations were } \\
\text { performed by mimicking } \\
\text { gastric, intestine and colon } \\
\text { conditions }\end{array}$ & $\begin{array}{l}\text { Resulted in large increases in Bacteroides and Collinsella, } \\
\text { moderate increases of specific Firmicutes, Enterobacteriaceae } \\
\text { and Bilophila }\end{array}$ & $(156)$ \\
\hline & (1) & $\begin{array}{l}\text { Microarray } \\
\text { analysis 2-DE } \\
\text { MALDI-TOF/ } \\
\text { TOF-MS } \\
\text { CE-MS } \\
\text { UPLC-Q/TOF- } \\
\text { MS }\end{array}$ & $\begin{array}{l}\text { Human HT29 colon } \\
\text { cancer cell }\end{array}$ & Rosemary polyphenols against colon cancer cells & $(157)$ \\
\hline & Mulberry Leaf & $\begin{array}{l}\text { UPLC Triple TOF } \\
\text { MS/MS } \\
\text { GC-MS }\end{array}$ & SD rats & Gut Environment is Altered by Mulberry Leaf & $(158)$ \\
\hline Dietary polyphenols & & $\begin{array}{l}\text { CE-TOF MS } \\
\text { RP/UPLC-TOF } \\
\text { MS } \\
\text { HILIC/UPLC- } \\
\text { TOF MS }\end{array}$ & $\begin{array}{l}\text { Human HT29 colon } \\
\text { cancer cells }\end{array}$ & $\begin{array}{l}\text { Reduced glutathione/oxidized glutathione ratio and significant } \\
\text { alterations in polyamines content }\end{array}$ & (26) \\
\hline
\end{tabular}

can function for the hosts. Numerous studies we reviewed which based on in vitro experiments, used polyphenol extracts from natural foods or single polyphenol compounds to directly affect intestinal cells using foodomics approaches, and the results obtained may be different from the actual state in vivo.

In fact, the digestion process of polyphenols in the colon is highly complex, and gut microbiota play a very important role in the metabolism of polyphenols. Most of the digestion and metabolism of polyphenols is done through gut microbiota. Meanwhile, polyphenols also play a beneficial role in regulating the composition of gut microbiota, even if the results of in vitro experiments to explain the protective effect of polyphenols on the GI tract or the metabolism of polyphenols in the GI tract are not sufficient. Animal experiments or simulated GI experiments will reduce the variability in experimental results for further understanding of the GI protective effects of polyphenols. Integrating foodomics to elucidate the GI protective effects of polyphenols also has several limitations. Notably, polyphenols are a generic term for a class of compounds, and the polyphenols in different natural foods vary significantly. Not all polyphenols in natural foods have common beneficial biological activities, and natural foods may exert their biological activities through one or more polyphenol compounds. Thus further research on the biological activities of polyphenol monomers in natural foods is required to explore and understand the bioactive compounds in natural foods. For instance, foodomics technologies result in massive amounts of data, which require extensive bioinformatics analysis. The comparison with other studies is challenging, due to the lack of information at the molecular level of all cellular processes, which indicates that there are gaps in showing effectiveness. Coincidentally with the applications and continuous development of high throughput technologies, there is a demand to develop more comprehensive tools to shorten the data processing time. Despite current studies using combined analysis methods, 
there is a lack of comprehensive data at the molecular level. In the future, studies at multiple molecular levels of genes, proteins, and metabolites are required to comprehensively understand the GI protective effects of polyphenols.

\section{AUTHOR CONTRIBUTIONS}

WZ and SQ: Writing-Original Draft, Writing-Review \& Editing. XX: Software, Writing-Review \& Editing. YA: Reviewing \& Editing. LW: Supervision, Funding acquisition. KW: Conceptualization, Methodology, Writing-Review \& Editing.

\section{REFERENCES}

1. Man AWC, Xia N, Daiber A, Li H. The Roles of Gut Microbiota and Circadian Rhythm in the Cardiovascular Protective Effects of Polyphenols. Brit J Pharmacol (2020) 177(6):1278-93. doi: 10.1111/bph.14850

2. Myint KZ, Wu K, Xia Y, Fan Y, Gu J. Polyphenols From Stevia Rebaudiana (Bertoni) Leaves and Their Functional Properties. J Food Sci (2020) 9:240-8. doi: 10.1111/1750-3841.15017

3. Yan Z, Zhong Y, Duan Y, Chen Q, Li F. Antioxidant Mechanism of Tea Polyphenols and its Impact on Health Benefits. Anim Nutr (2020) 6(2):11523. doi: 10.1016/j.aninu.2020.01.001

4. Mirza-Aghazadeh-Attari M, Ekrami EM, Aghdas SAM, Mihanfar A, Hallaj S, Yousefi B, et al. Targeting PI3K/Akt/mTOR Signaling Pathway by Polyphenols: Implication for Cancer Therapy. Life Sci (2020) 117481. doi: $10.1016 /$ j.lfs.2020.117481

5. Hidalgo M, Oruna-Concha MJ, Kolida S, Walton GE, Kallithraka S, Spencer JPE, et al. Metabolism of Anthocyanins by Human Gut Microflora and Their Influence on Gut Bacterial Growth. J Agric Food Chem (2012) 60:3882-90. doi: 10.1021/jf3002153

6. Scalbert A, Manach C, Morand C, Rémésy C, Jiménez L. Dietary Polyphenols and the Prevention of Diseases. Crit Rev Food Sci (2005) 45:287-306. doi: 10.1080/1040869059096

7. Stoclet JC, Chataigneau T, Ndiaye M, Oak MH, El Bedoui J, Chataigneau M, et al. Vascular Protection by Dietary Polyphenols. Eur J Pharmacol (2004) 500:299-313. doi: 10.1016/j.ejphar.2004.07.034

8. Moreno-Indias I, Sanchez-Alcoholado L, Perez-Martinez P, Andres-Lacueva C, Cardona F, Tinahones F, et al. Red Wine Polyphenols Modulate Fecal Microbiota and Reduce Markers of the Metabolic Syndrome in Obese Patients. Food Funct (2016) 7:1775-87. doi: 10.1039/c5fo00886g

9. Catalkaya G, Venema K, Lucini L, Rocchetti G. Interaction of Dietary Polyphenols and Gut Microbiota: Microbial Metabolism of Polyphenols, Influence on the Gut Microbiota and Implications on Host Health. Food Frontiers (2020) 1:109-33. doi: 10.1002/fft2.25

10. Singh B, Mal G, Sharma D, Sharma R, Chakkiath A, Kalra P, et al. Gastrointestinal Biotransformation of Phytochemicals: Towards Futuristic Dietary Therapeutics and Functional Foods. Trends Food Sci Tech (2020) 106:64-77. doi: 10.1016/j.tifs.2020.09.022

11. Sugiharto S. Role of Nutraceuticals in Gut Health and Growth Performance of Poultry. J Saudi Soc Agric Sci (2016) 15(2):99-111. doi: 10.1016/ j.jssas.2014.06.001 S1658077X400037X.

12. Nash V, Ranadheera CS, Georgousopoulou EN, Mellor DD, Panagiotakos DB, McKune AJ, et al. The Effects of Grape and Red Wine Polyphenols on Gut Microbiota - A Systematic Review. Food Res Int (2018) 113:277-87. doi: 10.1016/j.foodres.2018.07.019

13. Round JL, Mazmanian SK. The Gut Microbiota Shapes Intestinal Immune Responses During Health and Disease. Nat Rev Immunol (2009) 9:600. doi: $10.1038 /$ nri2614

14. Michael C, Anthony B. The Impact of Diet and Lifestyle on Gut Microbiota and Human Health. Nutrients (2014) 7(1):17-44. doi: 10.3390/nu7010017

15. Mithul Aravind S, Wichienchot, Tsao, Ramakrishnan, Chakkaravarthi. Role of Dietary Polyphenols on Gut Microbiota, Their Metabolites and Health Benefits. Food Res Int (2021) 142:110189. doi: 10.1016/j.foodres.2021.110189
All authors contributed to the article and approved the submitted version.

\section{FUNDING}

This work was supported by the National Natural Science Foundation of China under Grant (No. 31702287); the Agricultural Science and Technology Innovation Program under Grant (talent training programs, No. 180818); and the earmarked fund for Modern Agroindustry Technology Research System from the Ministry of Agriculture of China under Grant (CARS-45).

16. Duda-Chodak A, Tarko T, Satora P, Sroka P. Interaction of Dietary Compounds, Especially Polyphenols, With the Intestinal Microbiota: A Review. Eur J Nutr (2015) 54:325-41. doi: 10.1007/s00394-015-0852-y

17. Cardona F, Andrés-Lacueva C, Tulipani S, Tinahones FJ, Queipo-Ortuño MI. Benefits of Polyphenols on Gut Microbiota and Implications in Human Health. J Nutr Biochem (2013) 24:1415-22. doi: 10.1016/j.jnutbio. 2013.05.001

18. Trompette A, Gollwitzer ES, Yadava K, Sichelstiel AK, Sprenger N, NgomBru C, et al. Gut Microbiota Metabolism of Dietary Fiber Influences Allergic Airway Disease and Hematopoiesis. Nat Med (2014) 20:159-66. doi: $10.1038 / \mathrm{nm} .3444$

19. Li H, Christman LM, Li R, Gu L. Synergic Interactions Between Polyphenols and Gut Microbiota in Mitigating Inflammatory Bowel Diseases. Food Funct (2020) 11:4878-91. doi: 10.1039/d0fo00713g

20. Pandey KB, Rizvi SI. Plant Polyphenols as Dietary Antioxidants in Human Health and Disease. Oxid Med Cell Longev (2009) 2:270-78. doi: 10.4161/ oxim.2.5.9498

21. Selma MV, Espin JC, Tomas-Barberan FA. Interaction Between Phenolics and Gut Microbiota: Role in Human Health. J Agric Food Chem (2009) 57:6485-501. doi: 10.1021/jf902107d

22. Bowey E, Adlercreutz H, Rowland I. Metabolism of Isoflavones and Lignans by the Gut Microflora: A Study in Germ-Free and Human Flora Associated Rats. Food Chem Toxicol (2003) 41:0-636. doi: 10.1016/S0278-6915(02) 00324-1

23. Hui CL, Jenner AM, Low CS, Lee YK. Effect of Tea Phenolics and Their Aromatic Fecal Bacterial Metabolites on Intestinal Microbiota. Res Microbiol (2006) 157:0-884. doi: 10.1016/j.resmic.2006.07.004

24. Tomas-Barberan FA, Selma MV, Espin JC. Interactions of Gut Microbiota With Dietary Polyphenols and Consequences to Human Health. Curr Opin Clin Nutr Metab Care (2016) 19:471-76. doi: 10.1097/MCO.0000000000000314

25. Cifuentes A. Food Analysis and Foodomics. J Chromatogr A (2009) 1216:7109-09. doi: 10.1016/j.chroma.2009.09.018

26. Ibáñez C, Simó C, García-Cañas V, Gómez-Martínez A, Ferragut JA, Cifuentes A. Ce/Lc-MS Multiplatform for Broad Metabolomic Analysis of Dietary Polyphenols Effect on Colon Cancer Cells Proliferation. Electrophoresis (2012) 33:2328-36. doi: 10.1002/elps.201200143

27. Crespy V, Morand C, Manach C, Besson C, Demigne C, Remesy C. Part of Quercetin Absorbed in the Small Intestine Is Conjugated and Further Secreted in the Intestinal Lumen. Am J Physiol (1999) 277:120-6. doi: 10.1046/j.1365-201X.1999.00560.x

28. Tugba O, Sela DA, Jianbo X, Dilek B, Fang C, Esra C. The Reciprocal Interactions Between Polyphenols and Gut Microbiota and Effects on Bioaccessibility. Nutrients (2016) 8:78. doi: 10.3390/nu8020078

29. Espín JC, González-Sarrías A, Tomás-Barberán FA. The Gut Microbiota: A Key Factor in the Therapeutic Effects of (Poly)Phenols. Biochem Pharmacol (2017) 139:82-93. doi: 10.1016/j.bcp.2017.04.033

30. Denev P, Kratchanova M, Ciz M, Lojek A, Vasicek O, Nedelcheva P, et al. Biological Activities of Selected Polyphenol-Rich Fruits Related to Immunity and Gastrointestinal Health. Food Chem (2014) 157(15):37-44. doi: 10.1016/ j.foodchem.2014.02.022

31. Xia T, Duan WH, Zhang ZJ, Li SP, Zhao YX, Geng BB, et al. PolyphenolRich Vinegar Extract Regulates Intestinal Microbiota and Immunity and 
Prevents Alcohol-Induced Inflammation in Mice. Food Res Int (2020) 140. doi: 10.1016/j.foodres.2020.110064

32. Zhao Y, Jiang Q. Roles of the Polyphenol-Gut Microbiota Interaction in Alleviating Colitis and Preventing Colitis-Associated Colorectal Cancer. $A d v$ Nutr (2020) 1:546-65. doi: 10.1093/advances/nmaa104

33. Zhang B, Zhang YJ, Li HY, Deng ZY, Tsao R. A Review on Insoluble-Bound Phenolics in Plant-Based Food Matrix and Their Contribution to Human Health With Future Perspectives. Trends Food Sci Tech (2020) 105:347-62. doi: $10.1016 /$ j.tifs.2020.09.029

34. Peng M, Aryal U, Cooper B, Biswas D. Metabolites Produced During the Growth of Probiotics in Cocoa Supplementation and the Limited Role of Cocoa in Host-Enteric Bacterial Pathogen Interactions. Food Control (2015) 53:124-33. doi: 10.1016/j.foodcont.2015.01.014

35. Saebyeol, Jang, Jianghao, Sun, Pei, Chen, et al. Flavanol-Enriched Cocoa Powder Alters the Intestinal Microbiota, Tissue and Fluid Metabolite Profiles, and Intestinal Gene Expression in Pigs. J Nutr (2016) 165(4):67380. doi: $10.3945 /$ jn. 115.222968

36. Magistrelli D, Zanchi R, Malagutti L, Galassi G, Canzi E, Rosi F. Effects of Cocoa Husk Feeding on the Composition of Swine Intestinal Microbiota. J Agr Food Chem (2016) 2046:2046-52. doi: 10.1021/acs.jafc.5b05732

37. Lvarez-Cilleros D, Ramos S, María Elvira L-O, Fernando E, María ngeles M. Cocoa Diet Modulates Gut Microbiota Composition and Improves Intestinal Health in Zucker Diabetic Rats. Food Res Int (2020) 132:109058. doi: 10.1016/j.foodres.2020.109058

38. Mariona CB, Pérez-Cano Francisco J, Franch ', Margarida C. Gut Microbiota in a Rat Oral Sensitization Model: Effect of a Cocoa-Enriched Diet. Oxid Med Cell Longev (2017) 7417505. doi: 10.1155/2017/7417505

39. Abril-Gil M, Francisco JP-C, Ȧngels F, Castell M. Effect of a Cocoa-Enriched Diet on Immune Response and Anaphylaxis in a Food Allergy Model in Brown Norway Rats. J Nutr Biochem (2016) 27:317-26. doi: 10.1016/ j.jnutbio.2015.09.022

40. Massot-Cladera M, Pérez-Berezo T, Franch A, Castell M, Pérez-Cano FJ. Cocoa Modulatory Effect on Rat Faecal Microbiota and Colonic Crosstalk. Arch Biochem Biophys (2012) 527:105-12. doi: 10.1016/j.abb.2012.05.015

41. Etxeberria U, Fernandez-Quintela A, Milagro FI, Aguirre L, Portillo MP. Impact of Polyphenols and Polyphenol-Rich Dietary Sources on Gut Microbiota Composition. J Agr Food Chem (2013) 61:9517-33. doi: 10.1016/j.bcp.2017.04.033

42. Cueva C, Sanchez-Patan F, Monagas M, Walton GE, Gibson GR, Martin-Alvarez PJ, et al. In Vitro Fermentation of Grape Seed flavan-3-ol Fractions by Human Faecal Microbiota: Changes in Microbial Groups and Phenolic Metabolites. FEMS Microbiol Ecol (2013) 3):792-805. doi: 10.1111/1574-6941.12037

43. Mayer R, Stecher G, Wuerzner R, Silva RC, Sultana T, Trojer L, et al. Proanthocyanidins: Target Compounds as Antibacterial Agents. J Agr Food Chem (2008) 56(16):6959-66. doi: 10.1021/jf800832r

44. Pozuelo MJ, Agis-Torres A, Hervert-Hernandez D, Lopez-Oliva ME, Mufioz-Martinez E, Rotger R, et al. Grape Antioxidant Dietary Fiber Stimulates Lactobacillus Growth in Rat Cecum. J Food Sci (2012) 77:H5962. doi: 10.1111/j.1750-3841.2011.02520.x

45. Viveros A, Chamorro S, Pizarro M, Arija I, Centeno C, Brenes A. Effects of Dietary Polyphenol-Rich Grape Products on Intestinal Microflora and Gut Morphology in Broiler Chicks. Poult (2011) 90:566-78. doi: 10.3382/ ps.2010-00889

46. Prasad S, Tyagi AK, Aggarwal BB. Recent Developments in Delivery, Bioavailability, Absorption and Metabolism of Curcumin: The Golden Pigment From Golden Spice. Cancer Res Treat Off J Korean Cancer Assoc (2014) 46:2-18. doi: 10.4143/crt.2014.46.1.2

47. Garcia-Lazaro RS, Lamdan H, Caligiuri LG, Lorenzo N, Farina HG. In Vitro and In Vivo Antitumor Activity of Yerba Mate Extract in Colon Cancer Models: Antitumor Activity of Yerba Mate Extract in Colon Cancer Models. J Food Sci (2020) 85(7):2186-97. doi: 10.1111/1750-3841.15169

48. Haratifar S, Meckling KA, Corredig M. Antiproliferative Activity of Tea Catechins Associated With Casein Micelles, Using HT29 Colon Cancer Cells. J Dairy Sci (2014) 97:672-78. doi: 10.3168/jds.2013-7263

49. Eid N, Enani S, Walton G, Corona G, Costabile A, Gibson G, et al. The Impact of Date Palm Fruits and Their Component Polyphenols, on Gut Microbial Ecology, Bacterial Metabolites and Colon Cancer Cell Proliferation. J Nutr Sci (2014) 3:e46. doi: 10.1017/jns.2014.16
50. Brown EM, Gill CIR, McDougall GJ, Steward D. Mechanisms Underlying the Anti-Proliferative Effects of Berry Components in In Vitro Models of Colon Cancer. Curr Pharm Biotechnol (2012) 13:-. doi: 10.2174/ 138920112798868773

51. Vu KD, Hélène C, Bouvet J, Jacinthe CT, Doyon G, Sylvain JFO, et al. Effect of Different Cranberry Extracts and Juices During Cranberry Juice Processing on the Antiproliferative Activity Against Two Colon Cancer Cell Lines. Food Chem (2012) 132:959-67. doi: 10.1016/j.foodchem. 2011.11.078

52. Yi J, Wang Z, Bai H, Li L, Zhao H, Cheng C, et al. Polyphenols From Pinecones of Pinus Koraiensis Induce Apoptosis in Colon Cancer Cells Through the Activation of Caspase In Vitro. RSC Adv (2016) 6:5278-87. doi: $10.1039 / \mathrm{c} 5 \mathrm{ra} 24913 \mathrm{a}$

53. Hakura A, Seki Y, Sonoda J, Hosokawa S, Aoki T, Suganuma A, et al. Rapid Induction of Colonic Adenocarcinoma in Mice Exposed to Benzo[a]Pyrene and Dextran Sulfate Sodium. Food Chem Toxicol Int J Published Br Ind Biol Res Assoc (2011) 49:2997-3001. doi: 10.1016/j.fct.2011.07.057

54. Li H, Christman LM, Li R, Gu L. Synergic Interactions Between Polyphenols and Gut Microbiota in Mitigating Inflammatory Bowel Diseases. Food Funct (2020) 11:4878-91. doi: 10.1039/d0fo00713g

55. Nunes S, Danesi F, Del Rio D, Silva P. Resveratrol and Inflammatory Bowel Disease: The Evidence So Far. Nutr Res Rev (2017) 31:85-97. doi: 10.1017/ s095442241700021x

56. Rahman SU, Li Y, Huang Y, Zhu L, Feng S, Wu J, et al. Treatment of Inflammatory Bowel Disease Via Green Tea Polyphenols: Possible Application and Protective Approaches. Inflammopharmacology (2018) 26:319-30. doi: 10.1007/s10787-018-0462-4

57. Giacometti J, Josic D. Foodomics in Microbial Safety. Trac-Trend Anal Chem (2013) 52:16-22. doi: 10.1016/j.trac.2013.09.003

58. Braconi D, Bernardini G, Millucci L, Santucci A. Foodomics for Human Health: Current Status and Perspectives. Expert Rev Proteomics (2018) 15:153-64. doi: 10.1080/14789450.2018.1421072

59. Mendes-Ferreira A, Olmo MLD, García-Martínez J, Pérez-Ortín JE. Functional Genomics in Wine Yeast: DNA Arrays and Next Generation Sequencing. Biol Microorg Grapes Must Wine (2017) 573-604 doi: 10.1007/ 978-3-319-60021-5

60. Mardis ER. Next-Generation Sequencing Platforms. Annu Rev Anal Chem (2013) 6:287-303. doi: 10.1146/annurev-anchem-062012-092628

61. Roh SW, Abell GCJ, Kim K-H, Nam Y-D, Bae J-W. Comparing Microarrays and Next-Generation Sequencing Technologies for Microbial Ecology Research. Trends Biotechnol (2010) 28:291-99. doi: 10.1016/j.tibtech.2010.03.001

62. Berlin K, Koren S, Chin CS, Drake JP, Landolin JM, Phillippy AM. Assembling Large Genomes With Single-Molecule Sequencing and Locality-Sensitive Hashing. Nat Biotechnol (2015) 33:623-30. doi: 10.1038/ nbt.3238

63. Pushkarev D, Neff NF, Quake SR. Single-Molecule Sequencing of an Individual Human Genome. Nat Biotechnol (2009) 27:847-50. doi: $10.1038 /$ nbt.1561

64. Tuberosa R, Frascaroli E, Salvi S. Leveraging Plant Genomics for Better and Healthier Food. Curr Opin Food Sci (2017) 16:100-05. doi: 10.1016/ j.cofs.2017.09.006

65. Solieri L, Dakal TC, Giudici P. Next-Generation Sequencing and its Potential Impact on Food Microbial Genomics. Ann Microbiol (2012) 63(1):21-37. doi: 10.1007/s13213-012-0478-8

66. Valdés A, Ibáñez C, Simó C, García-Cañas V. Recent Transcriptomics Advances and Emerging Applications in Food Science. Trends Analytical Chem (2013) 52:142-54. doi: 10.1016/j.trac.2013.06.014

67. Pareek CS, Smoczynski R, Tretyn A. Sequencing Technologies and Genome Sequencing. J Appl Genet (2011) 52(4):413-35. doi: 10.1007/s13353-0110057-x

68. Malone JH, Oliver B. Microarrays, Deep Sequencing and the True Measure of the Transcriptome. BMC Biol (2011) 9:34. doi: 10.1186/1741-7007-9-34

69. Valdés A, Cifuentes A, León C. Foodomics Evaluation of Bioactive Compounds in Foods. Trac-Trend Anal Chem (2017) 15(1):416-24. doi: 10.1016/j.trac.2017.06.004 S0165993617301541

70. Tell-Marti G, Puig Sarda S, Puig-Butille JA. Gene Expression Microarray: Technical Fundamentals and Data Analysis. Compr Foodomics (2021), 291312. doi: 10.1016/B978-0-08-100596-5.22905-3 
71. Wilhelm BT, Landry JR. RNA-Seq-Quantitative Measurement of Expression Through Massively Parallel RNA-Sequencing. Methods (2009) 48:0-257. doi: 10.1016/j.ymeth.2009.03.016

72. Wang Z, Gerstein M, Snyder M. RNA-Seq: A Revolutionary Tool for Transcriptomics. Nat Rev Genet (2010) 10:57-63. doi: 10.1038/nrg2484

73. Lancova K, Dip R, Antignac JP, Bizec BL, Naegeli H. Detection of Hazardous Food Contaminants by Transcriptomics Fingerprinting. Trac-Trend Anal Chem (2011) 30:181-91. doi: 10.1016/j.trac.2010.10.013

74. Saito K, Ohta Y, Sami M, Kanda T, Kato H. Effect of Mild Restriction of Food Intake on Gene Expression Profile in the Liver of Young Rats: Reference Data for In Vivo Nutrigenomics Study. Br J Nutr (2010) 104:941-50. doi: $10.1017 / S 0007114510001625$

75. Aebersold R, Mann M. Mass-Spectrometric Exploration of Proteome Structure and Function. Nature (2016) 537(7620):347-55. doi: 10.1038/ nature19949

76. Bantscheff M, Kuster B. Quantitative Mass Spectrometry in Proteomics. Anal Bioanal Chem (2012) 404(4):937-38. doi: 10.1007/s00216-012-6261-7

77. Aebersold R, Mann M. Mass Spectrometry-Based Proteomics. Nature (2003) 422(6928):198-207. doi: 10.1038/nature01511

78. Wu Q, Yuan H, Zhang L, Zhang Y. Recent Advances on Multidimensional Liquid Chromatography-Mass Spectrometry for Proteomics: From Qualitative to Quantitative Analysis-A Review. Anal Chim Acta (2012) 731:1-10. doi: 10.1016/j.aca.2012.04.010

79. Chandramouli K, Qian P-Y. Proteomics: Challenges, Techniques and Possibilities to Overcome Biological Sample Complexity. Hum Genomics Proteomics (2009) 2009:1-22. doi: 10.4061/2009/239204

80. Arumugam M, Raes J, Pelletier E, Le Paslier D, Yamada T, Mende DR, et al. Enterotypes of the Human Gut Microbiome. Nature (2011) 473:174-80. doi: 10.1038/nature09944

81. Ferranti P. The Future of Analytical Chemistry in Foodomics. Curr Opin Food Sci (2018) 22:102-08. doi: 10.1016/j.cofs.2018.02.005

82. Zhang Y, Fonslow BR, Shan B, Baek MC, Yates JR. Protein Analysis by Shotgun/Bottom-Up Proteomics. Chem Rev (2013) 113:2343-94. doi: $10.1021 / \mathrm{cr} 3003533$

83. Tholey A, Becker A. Top-Down Proteomics for the Analysis of Proteolytic Events - Methods, Applications and Perspectives. Bba-Mol Cell Res (2017) 1864(11):2191-99. doi: 10.1016/j.bbamcr.2017.07.002

84. D'Alessandro A, Zolla L. We Are What We Eat: Food Safety and Proteomics. J Proteome Res (2012) 11:26-36. doi: 10.1021/pr2008829

85. Incamps A, Florence H-J, Chagvardieff P, Rambourg JC, Dedieu A, Linares E, et al. Industrial Process Proteomics: Alfalfa Protein Patterns During Wet Fractionation Processing. Biotechnol Bioeng (2010) 91:447-59. doi: 10.1002/ bit. 20520

86. Almeida AM, Bassols A, Bendixen E, Bhide M, Ceciliani F, Cristobal S, et al. Animal Board Invited Review: Advances in Proteomics for Animal and Food Sciences. Animal (2015) 9(1):1-17. doi: 10.1017/S1751731114002602

87. Gašo S. Dajana, Kovač, Spomenka, Josić, Djuro. Application of Proteomics in Food Technology and Food Biotechnology: Process Development, Quality Control and Product Safety. Food Technol Biotech (2010) 48(3):284-95. doi: 10.1016/j.foodres.2010.05.012

88. Koda M, Furihata K, Wei F, Miyakawa T, Tanokura M. Metabolic Discrimination of Mango Juice From Various Cultivars by Band-Selective Nmr Spectroscopy. J Agric Food Chem (2012) 60:1158-66. doi: 10.1002/ bit. 20520

89. Valdés A, Cifuentes A, León C. Foodomics Evaluation of Bioactive Compounds in Foods. Trac-Trend Anal Chem (2017) 96(SI):2-13. doi: 10.1016/j.trac.2017.06.004 S0165993617301541.

90. Cevallos-Cevallos JM, Reyes-De-Corcuera JI, Etxeberria E, Danyluk MD, Rodrick GE. Metabolomic Analysis in Food Science: A Review. Trends Food Sci Tech (2009) 20:0-566. doi: 10.1016/j.tifs.2009.07.002

91. Xu YJ, Wang C, Wanxing E, Ong HO. Recent Developments and Applications of Metabolomics in Microbiological Investigations. Trends Analytical Chem (2014) 56:37-48. doi: 10.1016/j.trac.2013.12.009

92. Xu YJ, Wu X. Foodomics in Microbiological Investigations. Curr Opin Food Sci (2015) 4:51-5. doi: 10.1016/j.cofs.2015.05.001

93. Miggiels P, Wouters B, van Westen GJP, Dubbelman A-C, Hankemeier T. Novel Technologies for Metabolomics: More for Less. Trac-Trend Anal Chem (2019) 120:115323. doi: 10.1016/j.trac.2018.11.021
94. Emwas AH. The Strengths and Weaknesses of NMR Spectroscopy and Mass Spectrometry With Particular Focus on Metabolomics Research. Methods Mol Biol (2015) 1277:161-93. doi: 10.1007/978-1-4939-2377-9_13

95. Misjudeen R, Amad A-H. Emwas Dehydrodimerization of Pterostilbene During Electrospray Ionization Mass Spectrometry. Rapid Commun Mass Sp (2013) 27:1260-66. doi: 10.1002/rcm.6571

96. Liu YR, Xiao B-K, Yang J-Y, Guo C-H, Shen S-J, Tang Z-S, et al. 1h-NMR and HPLC-MS/MS-based Global/Targeted Metabolomic Evaluation of Hypericum Perforatum L. Intervention for Menopause. J Funct Food (2015) 17:722-41. doi: 10.1016/j.jff.2015.06.023

97. Kohler I, Giera M. Recent Advances in Liquid-Phase Separations for Clinical Metabolomics. J Sep Sci (2017) 40:93-108. doi: 10.1002/jssc.201600981

98. Laghi L, Picone G, Capozzi F. Nuclear Magnetic Resonance for Foodomics Beyond Food Analysis. Trac-Trend Anal Chem (2014) 59:93-102. doi: 10.1016/j.trac.2014.04.009

99. Castro-Puyana M, Perez-Miguez R, Montero L, Herrero M. Application of Mass Spectrometry-Based Metabolomics Approaches for Food Safety, Quality and Traceability. Trac-Trend Anal Chem (2017) 93:102-18. doi: 10.1016/j.trac.2017.05.004

100. Castro-Puyana M, Herrero M. Metabolomics Approaches Based on Mass Spectrometry for Food Safety, Quality and Traceability. Trac-Trend Anal Chem (2013) 52:74-87. doi: 10.1016/j.trac.2013.05.016

101. Manach C, Brennan L, Dragsted LO. Using Metabolomics to Evaluate Food Intake. Metabol As Tool Nutr Res (2015) 167-96. doi: 10.1016/B978-178242-084-2.00009-5

102. Álvarez-Rivera G, Valdés A, León C, Cifuentes A. (2021), 1-53. doi: 10.1039/ 9781839163005-00001 Foodomics - Fundamentals, State of the Art and Future Trends.

103. Héberger K. Chemoinformatics-Multivariate Mathematical-Statistical Methods for Data Evaluation. Med Appl Mass Spectrometry (2018) 14169. doi: 10.1016/B978-044451980-1.50009-4

104. Latorre CH, Crecente RMP, Martin SG, Garcia JB. A Fast Chemometric Procedure Based on NIR Data for Authentication of Honey With Protected Geographical Indication. Food Chem (2013) 141:3559-65. doi: 10.1016/ j.foodchem.2013.06.022

105. Weinhold B. Epigenetics: The Science of Change. Environ Health Persp (2006) 114(3):A160-7. doi: 10.1289/ehp.114-a160

106. Martin K, Lutz K, Winfried S. Nutrigenomics: Where Are We With Genetic and Epigenetic Markers for Disposition and Susceptibility? Nutr Rev (2010) 68(suppl_1):S38-47. doi: 10.1111/j.1753-4887.2010.00326.x

107. Hawkins RD, Hon GC, Ren B. Next-Generation Genomics: An Integrative Approach. Nat Rev Genet (2010) 11:476-86. doi: 10.1038/nrg2795

108. Bao R, Huang L, Andrade J, Tan W, Kibbe WA, Jiang H, et al. Review of Current Methods, Applications, and Data Management for the Bioinformatics Analysis of Whole Exome Sequencing. Cancer Inf (2014) 13(s2):284-95. doi: 10.4137/CIN.S13779 CIN.S13779

109. Puiggros F, Sola R, Blade C, Salvado MJ, Arola L. Nutritional Biomarkers and Foodomic Methodologies for Qualitative and Quantitative Analysis of Bioactive Ingredients in Dietary Intervention Studies. J Chromatogr A (2011) 1218:7399-414. doi: 10.1016/j.chroma.2011.08.051

110. Matthew PG, Barnett J, Cooney M, Matthew PG, Barnett J, Cooney M, et al. Modulation of Colonic Inflammation in Mdrla-/- Mice by Green Tea Polyphenols and Their Effects on the Colon Transcriptome and Proteome. J Nutr Biochem (2013) 24(10):1678-90. doi: 10.1016/j.jnutbio.2013.02.007

111. Bao T, Xu Y, Gowd V, Zhao J, Xie J, Liang W, et al. Systematic Study on Phytochemicals and Antioxidant Activity of Some New and Common Mulberry Cultivars in China. J Funct Food (2016) 25:537-47. doi: 10.1016/j.jff.2016.07.001

112. Oszmianski J, Kolniak-Ostek J, Wojdylo A. Characterization of Phenolic Compounds and Antioxidant Activity of Solanum Scabrum and Solanum Burbankii Berries. J Agric Food Chem (2014) 62:1512-9. doi: 10.1021/jf4045233

113. Acero N, Gradillas A, Beltran M, García A, Muñoz Mingarro D. Comparison of Phenolic Compounds Profile and Antioxidant Properties of Different Sweet Cherry (Prunus Avium L.) Varieties. Food Chem (2019) 279:260-71. doi: 10.1016/j.foodchem.2018.12.008

114. Guo C, Bi J, Li X, Lyu J, Wu X, Xu Y. Polyphenol Metabolic Diversity of Chinese Peach and Nectarine at Thinned and Ripe Stages by UPLC-ESI-QTOF-MS Combined With Multivariate Statistical Analysis. J Food Compos Anal (2020) 90:103502. doi: 10.1016/j.jfca.2020.103502 
115. Antoniolli A, Fontana AR, Piccoli P, Bottini R. Characterization of Polyphenols and Evaluation of Antioxidant Capacity in Grape Pomace of the Cv. Malbec. Food Chem (2015) 178:172-78. doi: 10.1016/ j.foodchem.2015.01.082

116. López-Gutiérrez N, Romero-González R, Martínez Vidal JL, Frenich AG. Determination of Polyphenols in Grape-Based Nutraceutical Products Using High Resolution Mass Spectrometry. LWT-Food Sci Technol (2016) 71:24959. doi: $10.1016 /$ j.lwt.2016.03.037

117. Nkuimi Wandjou JG, Sut S, Giuliani C, Fico G, Papa F, Ferraro S, et al. Characterization of Nutrients, Polyphenols and Volatile Components of the Ancient Apple Cultivar 'Mela Rosa Dei Monti Sibillini' From Marche Region, Central Italy. Int J Food Sci Nutr (2019) 70:796-812. doi: 10.1080/ 09637486.2019.1580684

118. Abdulla R, Mansur S, Lai H, Ubul A, Sun G, Huang G, et al. Qualitative Analysis of Polyphenols in Macroporous Resin Pretreated Pomegranate Husk Extract by HPLC-QTOF-MS. Phytochem Anal (2017) 28:465-73. doi: $10.1002 /$ pca. 2695

119. Guo C, Qiao J, Zhang S, Ren X, Li M. Purification of Polyphenols From Kiwi Fruit Peel Extracts Using Macroporous Resins and High-Performance Liquid Chromatography Analysis. Int J Food Sci Tech (2018) 53:1486-93. doi: $10.1111 /$ ijfs. 13729

120. Athaydes BR, Alves GM, Assis A, Gomes JVD, Rodrigues RP, Campagnaro BP, et al. Avocado Seeds (Persea Americana Mill.) Prevents IndomethacinInduced Gastric Ulcer in Mice. Food Res Int (2019) 119:751-60. doi: 10.1016/ j.foodres.2018.10.057

121. Vallverdu-Queralt A, Boix N, Pique E, Gomez-Catalan J, Medina-Remon A, Sasot G, et al. Identification of Phenolic Compounds in Red Wine Extract Samples and Zebrafish Embryos by HPLC-ESI-LTQ-Orbitrap-MS. Food Chem (2015) 181:146-51. doi: 10.1016/j.foodchem.2015.02.098

122. Quifer-Rada P, Vallverdu-Queralt A, Martinez-Huelamo M, Chiva-Blanch G, Jauregui O, Estruch R, et al. A Comprehensive Characterisation of Beer Polyphenols by High Resolution Mass Spectrometry (LC-ESI-LTQOrbitrap-MS). Food Chem (2015) 169:336-43. doi: 10.1016/j.foodchem. 2014.07.154

123. Zhuang J, Dai X, Zhu M, Zhang S, Dai Q, Jiang X, et al. Evaluation of Astringent Taste of Green Tea Through Mass Spectrometry-Based Targeted Metabolic Profiling of Polyphenols. Food Chem (2020) 305:125507. doi: 10.1016/j.foodchem.2019.125507

124. Ramon-Goncalves M, Gomez-Mejia E, Rosales-Conrado N, Leon-Gonzalez ME, Madrid Y. Extraction, Identification and Quantification of Polyphenols From Spent Coffee Grounds by Chromatographic Methods and Chemometric Analyses. Waste Manag (2019) 96:15-24. doi: 10.1016/ j.wasman.2019.07.009

125. Ali F, Ranneh Y, Ismail A, Esa NM. Identification of Phenolic Compounds in Polyphenols-Rich Extract of Malaysian Cocoa Powder Using the HPLC-UVESI-MS/MS and Probing Their Antioxidant Properties. J Food Sci Technol (2015) 52:2103-11. doi: 10.1007/s13197-013-1187-4

126. Wang X, Zeng Q, Del Mar Contreras M, Wang L. Profiling and Quantification of Phenolic Compounds in Camellia Seed Oils: Natural Tea Polyphenols in Vegetable Oil. Food Res Int (2017) 102:184-94. doi: 10.1016/j.foodres.2017.09.089

127. Moreno-González R, Juan ME, Planas JM. Profiling of Pentacyclic Triterpenes and Polyphenols by LC-MS in Arbequina and Empeltre Table Olives. LWT (2020) 126:68-81. doi: 10.1016/j.lwt.2020.109310

128. Topi D, Guclu G, Kelebek H, Selli S. Comparative Elucidation of Phenolic Compounds in Albanian Olive Oils Using LC-DAD-ESI-MS/MS. J Liq Chromatogr R T (2020) 43:203-12. doi: 10.1080/10826076.2019.1711117

129. Wang X, Wang S, Huang S, Zhang L, Ge Z, Sun L, et al. Purification of Polyphenols From Distiller's Grains by Macroporous Resin and Analysis of the Polyphenolic Components. Molecules (2019) 24:1678-90. doi: 10.3390/ molecules 24071284

130. Kang J, Price WE, Ashton J, Tapsell LC, Johnson S. Identification and Characterization of Phenolic Compounds in Hydromethanolic Extracts of Sorghum Wholegrains by LC-ESI-MS(N). Food Chem (2016) 211:215-26. doi: 10.1016/j.foodchem.2016.05.052

131. Xiang J, Apea-Bah FB, Ndolo VU, Katundu MC, Beta T. Profile of Phenolic Compounds and Antioxidant Activity of Finger Millet Varieties. Food Chem (2019) 275:361-68. doi: 10.1016/j.foodchem.2018.09.120
132. Rao S, Santhakumar AB, Chinkwo KA, Blanchard CL. Q-Tof LC/MS Identification and UHPLC-Online ABTS Antioxidant Activity Guided Mapping of Barley Polyphenols. Food Chem (2018) 266:323-28. doi: 10.1016/j.foodchem.2018.06.011

133. Hajji T, Mansouri S, Vecino-Bello X, Cruz-Freire JM, Rezgui S, Ferchichi A. Identification and Characterization of Phenolic Compounds Extracted From Barley Husks by LC-MS and Antioxidant Activity In Vitro. J Cereal Sci (2018) 81:83-90. doi: 10.1016/j.jcs.2018.03.008

134. Santos MC, Toson NSB, Pimentel MCB, Bordignon SAL, Mendez ASL, Henriques AT. Polyphenols Composition From Leaves of Cuphea Spp. And Inhibitor Potential, In Vitro, of Angiotensin I-converting Enzyme (ACE). J Ethnopharmacol (2020) 255:112781. doi: 10.1016/j.jep.2020.112781

135. Pacifico S, Piccolella S, Nocera P, Tranquillo E, Dal Poggetto F, Catauro M. New Insights Into Phenol and Polyphenol Composition of Stevia Rebaudiana Leaves. J Pharmaceut BioMed (2019) 163:45-57. doi: 10.1016/j.jpba. 2018.09.046

136. Long W-J, Wu H-L, Wang T, Dong M-Y, Yu R-Q. Exploiting Second-Order Advantage From Mathematically Modeled Liquid Chromatography-Mass Spectrometry Data for Simultaneous Determination of Polyphenols in Chinese Propolis. Microchem J (2020) 157:105003. doi: 10.1016/ j.microc.2020.105003

137. Pereira OR, Peres AM, Silva AMS, Domingues MRM, Cardoso SM. Simultaneous Characterization and Quantification of Phenolic Compounds in Thymus X Citriodorus Using a Validated HPLC-UV and ESI-MS Combined Method. Food Res Int (2013) 54:1773-80. doi: 10.1016/ j.foodres.2013.09.016

138. Han B, Xin Z, Ma S, Liu W, Zhang B, Ran L, et al. Comprehensive Characterization and Identification of Antioxidants in Folium Artemisiae Argyi Using High-Resolution Tandem Mass Spectrometry. J Chromatogr B Analyt Technol BioMed Life Sci (2017) 1063:84-92. doi: 10.1016/ j.jchromb.2017.08.021

139. Hsu BY, Lin SW, Inbaraj BS, Chen BH. Simultaneous Determination of Phenolic Acids and Flavonoids in Chenopodium Formosanum Koidz. (Djulis) by HPLC-DAD-ESI-MS/MS. J Pharm BioMed Anal (2017) 132:109-16. doi: 10.1016/j.jpba.2016.09.027

140. Desta KT, Kim GS, Abd El-Aty AM, Raha S, Kim MB, Jeong JH, et al. Flavone Polyphenols Dominate in Thymus Schimperi Ronniger: Lc-ESI-MS/ MS Characterization and Study of Anti-Proliferative Effects of Plant Extract on AGS and HepG2 Cancer Cells. J Chromatogr B Analyt Technol BioMed Life Sci (2017) 1053:1-8. doi: 10.1016/j.jchromb.2017.03.035

141. Dolara P, Luceri C, De Filippo C, Femia AP, Giovannelli L, Caderni G, et al. Red Wine Polyphenols Influence Carcinogenesis, Intestinal Microflora, Oxidative Damage and Gene Expression Profiles of Colonic Mucosa in F344 Rats. Mutat Res (2005) 591:237-46. doi: 10.1016/j.mrfmmm. 2005.04.022

142. Liu Y, Luo L, Luo Y, Zhang J, Wang X, Sun K, et al. Prebiotic Properties of Green and Dark Tea Contribute to Protective Effects in Chemical-Induced Colitis in Mice: A Fecal Microbiota Transplantation Study. J Agric Food Chem (2020) 68:6368-80. doi: 10.1021/acs.jafc.0c02336

143. Anhê FF, Roy D, Pilon G, Dudonne S, Matamoros S, Varin TV, et al. A Polyphenol-Rich Cranberry Extract Protects From Diet-Induced Obesity, Insulin Resistance and Intestinal Inflammation in Association With Increased Akkermansia Spp. Population in the Gut Microbiota of Mice. Gut (2015) 64:872-83. doi: 10.1136/gutjnl-2014-307142

144. Cowan TE, Palmnäs MSA, Yang J, Bomhof MR, Ardell KL, Reimer RA, et al. Chronic Coffee Consumption in the Diet-Induced Obese Rat: Impact on Gut Microbiota and Serum Metabolomics. J Nutr Biochem (2014) 25:489-95. doi: 10.1016/j.jnutbio.2013.12.009

145. Roquetto AR, Santana Monteiro NE, Moura CS, Toreti VC, De Pace F, Dos Santos A, et al. Green Propolis Modulates Gut Microbiota, Reduces Endotoxemia and Expression of TLR4 Pathway in Mice Fed a High-Fat Diet. Food Res Int (2015) 76:796-803. doi: 10.1016/j.foodres.2015.07.026

146. Wang K, Jin XL, You MM, Tian WL, Le Leu RK, Topping DL, et al. Dietary Propolis Ameliorates Dextran Sulfate Sodium-Induced Colitis and Modulates the Gut Microbiota in Rats Fed a Western Diet. Nutrients (2017) 9:875. doi: 10.3390/nu9080875

147. Zhang X, Chen Y, Zhu J, Zhang M, Cao J. Metagenomics Analysis of Gut Microbiota in a High Fat Diet-Induced Obesity Mouse Model Fed With 
Epigallocatechin 3-O-(3-O-Methyl) Gallate (Egcg3"Me). Mol Nutr Food Res (2018) 62(13):5-6. doi: 10.1002/mnfr.201800274

148. Kaulmann A, Planchon S, Renaut J, Schneider YJ, Hoffmann L, Bohn T. Proteomic Response of Inflammatory Stimulated Intestinal Epithelial Cells to In Vitro Digested Plums and Cabbages Rich in Carotenoids and Polyphenols. Food Funct (2016) 7:4388-99. doi: 10.1039/c6fo00674d

149. Bermúdez-Soto MJ, Larrosa M, García-Cantalejo J, Espín JC, TomásBarberan FA, García-Conesa MT. Transcriptional Changes in Human Caco-2 Colon Cancer Cells Following Exposure to a Recurrent non-Toxic Dose of Polyphenol-Rich Chokeberry Juice. Genes Nutr (2007) 2:111-13. doi: 10.1007/s12263-007-0026-5

150. Bucio-Noble D, Kautto L, Krisp C, Ball MS, Molloy MP. Polyphenol Extracts From Dried Sugarcane Inhibit Inflammatory Mediators in an In Vitro Colon Cancer Model. J Proteomics (2018) 177:1-10. doi: 10.1016/j.jprot.2018.02.009

151. Dihal AA, Woude HVD, Hendriksen PJM, Charif H, Dekker LJ, Ijsselstijn L, et al. Transcriptome and Proteome Profiling of Colon Mucosa From Quercetin Fed F344 Rats Point to Tumor Preventive Mechanisms, Increased Mitochondrial Fatty Acid Degradation and Decreased Glycolysis. Proteomics (2008) 8:323-8. doi: 10.1002/pmic.200700364

152. Jacobs DM, Deltimple N, van Velzen E, van Dorsten FA, Bingham M, Vaughan EE, et al. (1)H NMR Metabolite Profiling of Feces as a Tool to Assess the Impact of Nutrition on the Human Microbiome. NMR BioMed (2008) 21:615-26. doi: 10.1002/nbm.1233

153. Van Dorsten FA, Peters S, Gross G, Gomez-Roldan V, Klinkenberg M, de Vos RC, et al. Gut Microbial Metabolism of Polyphenols From Black Tea and Red Wine/Grape Juice Is Source-Specific and Colon-Region Dependent. J Agr Food Chem (2012) 60:11331-42. doi: 10.1021/jf303165w

154. María AN-S, Rocío G-V, Monedero-Saiz T, Noelia VG-T, Juan CE. Targeted Metabolic Profiling of Pomegranate Polyphenols and Urolithins in Plasma, Urine and Colon Tissues From Colorectal Cancer Patients. Mol Nutr Food Res (2014) 58:1199-211. doi: 10.1002/mnfr.201300931

155. Garcia-Mazcorro JF, Pedreschi R, Yuan J, Kawas JR, Chew B, Dowd SE, et al. Apple Consumption is Associated With a Distinctive Microbiota, Proteomics and Metabolomics Profile in the Gut of Dawley Sprague Rats Fed a High-Fat Diet. PloS One (2019) 14:e212586. doi: 10.1371/journal.pone.0212586

156. Seidel, Derek V, Andrea Azcárate-Peril M. Robert S Chapkin, and Nancy D Turner. Shaping Functional Gut Microbiota Using Dietary Bioactives to Reduce Colon Cancer Risk. Semin Cancer Biol (2017) 46:191-204. doi: 10.1016/j.semcancer.2017.06.009

157. Mayta-Apaza AC, Pottgen E, De Bodt J, Papp N, Daya M, Luke H, et al. Impact of Tart Cherries Polyphenols on the Human Gut Microbiota and Phenolic Metabolites In Vitro and In Vivo. J Nutr Biochem (2018) 1063:16072. doi: 10.1016/j.jnutbio.2018.04.001

158. Qian LI, Fan L, Jun S, Qian LI, Fan L, Jun S. Mulberry Leaf Polyphenols and Fiber Induce Synergistic Antiobesity and Display a Modulation Effect on Gut Microbiota and Metabolites. Nutrients (2019) 11(5):109-16. doi: 10.3390/nul1051017

159. García-Canas V, Simó C, León C, Cifuentes A. Advances in Nutrigenomics Research: Novel and Future Analytical Approaches to Investigate the Biological Activity of Natural Compounds and Food Functions. J Pharm BioMed Anal (2010) 51:290-304. doi: 10.1016/j.jpba.2009.04.019

160. Valdés A, García-Cañas V, Rocamora-Reverte L, Gómez-Martínez A, Ferragut JA, Cifuentes A. Effect of Rosemary Polyphenols on Human Colon Cancer Cells: Transcriptomic Profiling and Functional Enrichment Analysis. Genes Nutr (2013) 2013:43-60. doi: 10.1007/s12263-012-0311-9

161. Wang J, Tang L, Zhou H, Zhou J, Glenn TC, Shen CL, et al. Long-Term Treatment With Green Tea Polyphenols Modifies the Gut Microbiome of Female Sprague-Dawley Rats. J Nutr Biochem (2018) 56:55-64. doi: 10.1016/ j.jnutbio.2018.01.005

162. Yang RP, Shan SH, Zhang C, Shi JY, Li HQ, Li ZY. Inhibitory Effects of Bound Polyphenol From Foxtail Millet Bran on Colitis-Associated
Carcinogenesis by the Restoration of Gut Microbiota in a Mice Model. J Agr Food Chem (2020) 68:3506-517. doi: 10.1021/acs.jafc.0c00370

163. Ruiz L, Hidalgo C, Blanco-Míguez A, Lourenço A, Sánchez B, Margolles A. Tackling Probiotic and Gut Microbiota Functionality Through Proteomics. J Proteomics (2016) 147:28-39. doi: 10.1016/j.jprot.2016.03.023

164. Valdés A, Artemenko KA, Bergquist J, Garcia-Cañas V, Cifuentes A. Comprehensive Proteomic Study of the Antiproliferative Activity of a Polyphenol-Enriched Rosemary Extract on Colon Cancer Cells Using Nanoliquid Chromatography-Orbitrap Ms/Ms. J Proteome Res (2016) 15:1971-85. doi: 10.1021/acs.jproteome.6b00154

165. Barnett MP, Cooney JM, Dommels YE, Nones K, Brewster DT, Park Z, et al. Modulation of Colonic Inflammation in Mdrla(-/-) Mice by Green Tea Polyphenols and Their Effects on the Colon Transcriptome and Proteome. J Nutr Biochem (2013) 24:1678-90. doi: 10.1016/j.jnutbio.2013.02.007

166. Li Z, Xie J, Tian X, Ke L, Hou A, Wang Y. Proteomic Changes in EHEC O157:H7 Under Catechin Intervention. Microb Pathogenesis (2018) 123:917. doi: 10.1016/j.micpath.2018.06.034

167. Pimentel G, Burton KJ, Vergères G, Dupont D. The Role of Foodomics to Understand the Digestion/Bioactivity Relationship of Food. Curr Opin Food Sci (2018) 22:67-73. doi: 10.1016/j.cofs.2018.02.002

168. Fernández-Arroyo S, Gómez-Martínez A, Rocamora-Reverte L, QuirantesPiné R, Segura-Carretero A, Fernández-Gutiérrez A, et al. Application of nanoLC-ESI-TOF-MS for the Metabolomic Analysis of Phenolic Compounds From Extra-Virgin Olive Oil in Treated Colon-Cancer Cells. J Pharmaceut BioMed (2012) 63:128-34. doi: 10.1016/j.jpba.2012.01.033

169. Li Q, Liang X, Guo N, Hu L, MP E, Wu Y, et al. Protective Effects of Bee Pollen Extract on the Caco-2 Intestinal Barrier Dysfunctions Induced by Dextran Sulfate Sodium. BioMed Pharmacother (2019) 117:109200. doi: 10.1016/j.biopha.2019.109200

170. Di Nunzio M, Picone G, Pasini F, Caboni MF, Gianotti A, Bordoni A, et al. Olive Oil Industry by-Products. Effects of a Polyphenol-Rich Extract on the Metabolome and Response to Inflammation in Cultured Intestinal Cell. Food Res Int (2018) 113:392-400. doi: 10.1016/j.foodres.2018.07.025

171. Ibánez C, Simó C, García-Canñs V, Gómez-Martínez á, Ferragut JA, Cifuentes A. Ce/Lc-MS Multiplatform for Broad Metabolomic Analysis of Dietary Polyphenols Effect on Colon Cancer Cells Proliferation. Electrophoresis (2012) 33:2328-36. doi: 10.1002/elps.201200143

172. Ibánez C, Valdés A, Garcia-Canñs V, Simo C, Celebier M, Rocamora-Reverte L, et al. Global Foodomics Strategy to Investigate the Health Benefits of Dietary Constituents. J Chromatogr A (2012) 1248:139-53. doi: 10.1016/ j.chroma.2012.06.008

173. Zhou J, Tang LL, Chwan-Li S, Wang J-S. Green Tea Polyphenols Modify Gut-Microbiota Dependent Metabolisms of Energy, Bile Constituents and Micronutrients in Female Sprague-Dawley Rats. J Nutr Biochem (2018) 61:68-81. doi: 10.1016/j.jnutbio.2018.07.018

174. Zhou J, Tang L, Shen C-L, Wang J-S. Green Tea Polyphenols Boost GutMicrobiota-Dependent Mitochondrial TCA and Urea Cycles in SpragueDawley Rats. J Nutr Biochem (2020) 108395. doi: 10.1016/j.jnutbio. 2020.108395

Conflict of Interest: The authors declare that the research was conducted in the absence of any commercial or financial relationships that could be construed as a potential conflict of interest.

Copyright $\odot 2021$ Zhang, Qi, Xue, Al Naggar, Wu and Wang. This is an open-access article distributed under the terms of the Creative Commons Attribution License (CC BY). The use, distribution or reproduction in other forums is permitted, provided the original author(s) and the copyright owner(s) are credited and that the original publication in this journal is cited, in accordance with accepted academic practice. No use, distribution or reproduction is permitted which does not comply with these terms. 